\title{
Insights on the Cellulose Pretreatment at Room Temperature by Choline-Chloride-Based Deep Eutectic Solvents: An Atomistic Study
}

Joel A. Sánchez-Badillo

Universidad Michoacana de San Nicolás de Hidalgo: Universidad Michoacana de San Nicolas de Hidalgo

Marco Gallo

Tecnológico Nacional de México: Tecnologico Nacional de Mexico

José G. Rutiaga-Quiñones

Universidad Michoacana de San Nicolás de Hidalgo: Universidad Michoacana de San Nicolas de Hidalgo

Jorge Garza

Universidad Autonoma Metropolitana Iztapalapa Division de Ciencias Basicas e Ingenieria

Pablo Lopez-Albarran ( $\sim$ plopez@umich.mx )

Universidad Michoacana de San Nicolas de Hidalgo https://orcid.org/0000-0001-9412-8635

\section{Research Article}

Keywords: Deep eutectic solvents, Cellulose pretreatment, Molecular dynamics simulations, Kamlet-Taft 37 parameters correlations, Solvent net basicity

Posted Date: February 21st, 2022

DOI: https://doi.org/10.21203/rs.3.rs-1273647/v1

License: (c) (i) This work is licensed under a Creative Commons Attribution 4.0 International License. Read Full License 


\section{Insights on the Cellulose Pretreatment at room Temperature by Choline-} Chloride-based Deep Eutectic Solvents: An Atomistic Study.

Joel A. Sánchez-Badilloa, Marco Gallob, José G. Rutiaga-Quiñonesa, Jorge Garzac, and Pablo LópezAlbarrán ${ }^{*}$

aFacultad de Ingeniería en Tecnología de la Madera, Universidad Michoacana de San Nicolás de Hidalgo, Edificio D, Ciudad Universitaria, Fco. J. Múgica S/N, Morelia, Michoacán, C. P. 58030, México. *Corresponding author, Tel.: +52 4431796238, email: plopez@umich.mx

bTecnológico Nacional de México/ITCJ, Av. Tecnológico No. 1340, Cd. Juárez, Chihuahua C. P. 32500, México. ‘Departamento de Química, División de Ciencias Básicas e Ingeniería, Universidad Autónoma MetropolitanaIztapalapa, San Rafael Atlixco No. 186, Iztapalapa, Ciudad de México, C. P. 09340, México.

\section{Abstract.}

The pretreatment or disruption of a cellulose $\mathrm{I} \beta$ crystallite, was described from the atomistic interactions evaluated at room temperature within four deep eutectic solvents: choline-chloride ethylene glycol, choline-chloride oxalic acid, choline-chloride urea, and choline-chloride levulinic acid. The analysis was based on the obtained correlations for the Kamlet-Taft $\alpha$ and $\beta$ parameters with a series of thermodynamic, structural, and energetic properties. The Kamlet-Taft parameters correlated with the thermodynamic properties of the solvent and their changes upon addition of the cellulose crystallite. Structural analysis revealed that the weaker the interactions within the molecules of solvent, the stronger the interactions between the hydroxyl group from cellulose with the chloride anion and with the hydrogen bond donor. Further analysis indicated that the $R-C O-R$ moieties in the hydrogen bond donor within the solvent, interacted better with the cellulose. The hydrogen bond occupancies within the cellulose crystallite, displayed that the main $06-H 6 \cdots O 2 / O 3$ and $02-H 2 \cdots O 6$ interchain hydrogen bonds in the glucan located at the edge of the solute were replaced by weak $06-H 6 \cdots O 4$ hydrogen bonds in all solvents. This effect was related to the $O-H \cdots C l, C-H \cdots O$, and $O \cdots H-O$ HBs between cellulose and DES molecules and confirmed by the non-covalent interactions obtained through DFT calculations. Finally, the energetic interactions and the atomistic degree of disruption of the cellulose crystallite were not completely described by the Kamlet-Taft $\beta$ or $\alpha$ parameters separately. Surprisingly, by using the net basicity $(\beta-\alpha)$ definition, such correlations were improved suggesting that both parameters must be considered in order to develop new, green, and sustainable solvents for cellulose pretreatment process.

\section{Keywords}

Deep eutectic solvents / Cellulose pretreatment / Molecular dynamics simulations / Kamlet-Taft parameters correlations / Solvent net basicity 
Introduction.

The global demand of energy is constantly increasing (Zhang et al. 2017), in consequence new efficient, ecological, and economic energy resources and processes are urgently needed (van Putten et al. 2013; Clarke et al. 2018; Körner et al. 2019). Lignocellulosic biomass (LCB) is the largest and greenest source of carbon on Earth (Tang et al. 2017; Körner et al. 2019). The use of the LCB as renewable source has been proposed to produce chemicals, materials, fuels, and energy, currently based on fossil oils (Gunny et al. 2015; Clarke et al. 2018; Tiong et al. 2018; Chen and Mu 2019; Zhou et al. 2020). The efficient use of LCB requires solvents capable to pretreating or dissolving its components (van Putten et al. 2013; Rocha et al. 2017; Tiong et al. 2018), namely, cellulose (40-80\%), hemicellulose (15-30\%), and lignin (10-25\%) (van Osch et al. 2017; Kumar et al. 2020). These processes facilitate accessibility of either incoming third particles (such as reactants, catalysts, etc.) or enzymes (Procentese et al. 2015), to produce valuable products. Unfortunately, the common solvents used for these purposes are organic solvents, $\mathrm{H}_{2} \mathrm{SO}_{4}, \mathrm{H}_{3} \mathrm{PO}_{4}$, and $\mathrm{NaOH}$, which are widely recognized by their potential environment concerns (Ren et al. 2016; Tang et al. 2017; Sert et al. 2018; Kumar et al. 2020).

A new class of solvents, including ionic liquids (ILs) and deep eutectic solvents (DESs) have been proposed for the LCB dissolution or its pretreatment (Swatloski et al. 2002; Pinkert et al. 2009; Francisco et al. 2012; Wang et al. 2012; Zhang et al. 2012; Sharma et al. 2013; Xia et al. 2014; Procentese et al. 2015; Ren et al. 2016; Tang et al. 2017; Clarke et al. 2018; Chen et al. 2019; Chen and Mu 2019; Kumar et al. 2020; Smirnov et al. 2020; Zhang et al. 2020). Despite their unique properties and the ability to dissolve LCB, the ILs (Swatloski et al. 2002; Pinkert et al. 2009; Wang et al. 2012; Kumar et al. 2020) have some drawbacks: high cost, complex synthesis, recycling problems, and toxicity issues (Rocha et al. 2017; Tang et al. 2017; Clarke et al. 2018) hindering their use at commercial or large scale. The DESs, also called low transition temperature mixtures (Rodríguez et al. 2015; Tang et al. 2017), are eutectic mixtures composed by a hydrogen bond acceptor (HBA) and a hydrogen bond donor (HBD) in a specific HBA:HBD molar ratio. Due to the high number of hydrogen bond interactions, low lattice energy values, and the asymmetry of HBA and HBD, the DESs have much lower melting point than their constituting components, yielding the liquid state of the mixture (Smith et al. 2014; Chen and Mu 2019). Despite the fact that DESs and ILs present similar physicochemical properties (Smith et al. 2014; García et al. 2015; Kalhor and Ghandi 2019), the DESs are low cost (Gorke et al. 2008; Kalhor and Ghandi 2019) easy to synthetize (Brett 2018), non-toxic (Halder and Cordeiro 2019), and biodegradable solvents (Tang et al. 2017). These properties make the DESs an attractive, economical, and green alternative for several applications (Lawes et al. 2010; Abo-Hamad et al. 2015; García et al. 2015; Rodríguez et al. 2015; Faggian et al. 2016; Brett 2018; Körner et al. 2019; Ünlü et al. 2019), including the LCB pretreatment and its conversion (Procentese et al. 2015; Chen and Mu 2019; Körner et al. 2019).

The experimental ability of common DESs, which include the choline-chloride $(\mathrm{ChCl})$ as $\mathrm{HBA}$, to dissolve the LCB is far from that reached by ILs (Francisco et al. 2012; Zhang et al. 2012; Sharma et al. 2013; van Osch et al. 2017; Chen et al. 2019; Morais et al. 2020). However, it has been reported that DESs 
are able to pretreat the LCB (Xia et al. 2014; Procentese et al. 2015; Kalhor and Ghandi 2019; Chen and $\mathrm{Mu}$ 2019), providing a green and novel way to synthesize valuable derivatives (Sirviö et al. 2015), Furthermore, DESs have been reported in studies to develop biomedical applications (Trache 2018), energy storage, food packaging, and catalysis (Trache et al. 2020). On this regard, the LCB pretreament with DESs can enhance subsequent steps on the biomass valorization (Xia et al. 2014; Procentese et al. 2015), such as enzymatic hydrolysis (Xia et al. 2014), or acting as an effective media for the cellulose modification (Sirviö et al. 2015; Tang et al. 2017; Smirnov et al. 2020), even at low temperatures (Gunny et al. 2015; Lu et al. 2016).

The LCB dissolution capacity of DESs has been related to the disruption of the hydrogen bonds (HBs) present in the biomass structure by action of the both the HBD and the anion in the HBA (Sharma et al. 2013; Ren et al. 2016; Lu et al. 2016; Häkkinen and Abbott 2019). Ren et al. (2016), Xia et al. (2018), and Liang et al. (2021) found that the experimental solubility of the LCB can be correlated to the ability of the DESs to donating or accepting protons, measured by the Kamlet-Taft $\alpha$ and $\beta$ parameters, respectively. Furthermore, Ren et al. (2016) also reported that the solubility of the cellulose can be associated with experimental thermodynamic properties of the pure DESs.

Nevertheless, there is a lack of fundamental knowledge regarding the basic interactions between DESs and biomass solutes, including carbohydrates (Mohan et al. 2017; van Osch et al. 2017). The development of new, green, sustainable, and efficient DESs in this field, needs to overcome these limitations. Molecular dynamics (MD) simulations have provided an efficient route to reveal, understand, and predict the microscopic interactions that drive the LCB dissolution (Wang et al. 2012; Mohan et al. 2017; van Osch et al. 2017; Xia et al. 2018; Fu et al. 2020; Smirnov et al. 2020; Zhou et al. 2020). Since the cellulose is the main component within the LCB (40-80\%) (van Osch et al. 2017; Kumar et al. 2020), and the high molecular complexity of the LCB, most of the LCB-DES theoretical works reported in the literature, are focused on the cellulose-DES (Smirnov et al. 2020), or glucose-DES (Mohan et al. 2017; Fu et al. 2020) systems. Interestingly, the majority of these studies explored the cellulose dissolution and not its pretreatment.

Mohan et al. (2017) and Smirnov et al. (2020) have used classical MD simulations to reveal the glucose-DES and the cellulose surface-DES interactions, respectively. The authors found, by means of radial distribution functions (RDFs), that the anion from the HBA and the HBD are the main interactions towards the carbohydrates, and therefore responsible of the glucose dissolution and the surface deconstruction process.

Recently, Fu et al. (2020) performed quantum chemical calculations in order to evaluate the strength of the interactions between the cellobiose and DES molecules. The authors found that HBs between the HBA and the HBD are weakened when they interact with the cellobiose. This interaction reduces the cellobiose hydroxyl bond strength, consequently, the cellobiose HB network becomes weaker, favoring its dissolution. 

dissolution or pretreatment process is still unclear (Chen et al. 2019). However, it seems that the HBs between solute and solvent might be the driving forces of such processes. These interactions can be 117 revealed through MD simulations, and they can be further described in terms of the hydrogen bond 118 basicity (Kamlet-Taft $\beta$ parameter), hydrogen bond acidity (Kamlet-Taft $\alpha$ parameter), and pure thermodynamic properties of the DESs, providing valuable information in order to develop sustainable solvents from in-silico calculations.

In the present work, the choline-chloride $(\mathrm{ChCl})$ was selected as $\mathrm{HBA}$, due to its large 122 biodegradability, high biocompatibility, low toxicity, low cost, and biomass-origin (Halder and Cordeiro 123 2019; Körner et al. 2019; Zhang et al. 2020). Consequently, we have selected the $\mathrm{ChCl} / \mathrm{ethylene} \mathrm{glycol}$ 124 (molar ratio 1:2), $\mathrm{ChCl} /$ oxalic acid (1:1), $\mathrm{ChCl} /$ urea (1:2), and the $\mathrm{ChCl} /$ levulinic acid (1:2) DESs due to their broad range of both viscosity (which spans from $41 \mathrm{cP}$ to $7600 \mathrm{cP}$ ) (D'Agostino et al. 2011; Florindo et al. 2014; Xie et al. 2014; Yadav and Pandey 2014; Chemat et al. 2016; Harifi-Mood and 127 Buchner 2017; Shekaari et al. 2017) and hydrogen bond basicity (from $\sim 0.3$ to $~ 0.6$ ) (Florindo et al. 128 2018; Kundu et al. 2020). Furthermore, the observed properties have been related with the capability of 129 DESs to dissolve cellulose (Ren et al. 2016).

The present study comprised two stages: (i) the DESs thermodynamic properties, their changes upon the addition of a cellulose I $\beta$ crystallite (cellulose-DES mixture), and their further relation with the Kamlet-Taft $\beta$ and $\alpha$ parameters values of the DESs, i.e. the solvent behavior point of view. (ii) A description on the ability of DESs to disrupt the cellulose $\mathrm{I} \beta$ crystallite and its relationship with the

134 Kamlet-Taft $\beta$ and $\alpha$ parameters of the DESs, i.e. the cellulose disruption from an atomistic perspective.

135 For such purposes, density $(\rho)$, molar volume $\left(V_{m}\right)$, cohesive energy density $(c)$, enthalpy of vaporization $136\left(\Delta H_{v a p}\right)$, Hildebrand parameter $(\delta), \mathrm{RDFs}$, cellulose-DES HBs (classical geometric and quantum 137 electronic density definition), HB occupancies, cellulose diffusion coefficient $\left(D_{\text {cellulose }}\right)$, non-bonded 138 potential energy of cellulose ( $E_{\text {non-bonde }}$,cellulose $)$, and short-range non-bonded pair energies $\left(E_{S R}\right)$ have been calculated for $\mathrm{ChCl}$ /ethylene glycol, $\mathrm{ChCl}$ /oxalic acid, $\mathrm{ChCl} /$ urea, and $\mathrm{ChCl} /$ levulinic acid DESs, as 141 at room temperature since desired green and sustainable applications require low energy consumptions 142 (Welton 2015; Clarke et al. 2018; Körner et al. 2019). To the best of our knowledge, there is scarce 143 literature information concerning the interactions between a cellulose crystallite $\mathrm{I} \beta$ model and $\mathrm{ChCl}$ 144 based DESs regarding the cellulose pretreatment, as well as thermodynamic and structural properties of cellulose-DES mixtures.

147 Computational methods.

148 Force fields.

149 All the ChCl-based DESs were modeled with the force fields (FFs) developed by Doherty and 150 Acevedo (2018), also-called OPLS-DES FF. These FFs use a $\pm 0.8 e$ scaled charge for the cations and anions 
present in the DES, providing a remarkable agreement between calculated and experimental properties including densities, viscosities, heat capacities, surface tensions, and diffusion coefficients (Doherty and Acevedo 2018). The corresponding HBA:HBD molar ratios for the evaluated $\mathrm{ChCl} /$ ethylene glycol, $\mathrm{ChCl} /$ oxalic acid, $\mathrm{ChCl} /$ urea, and $\mathrm{ChCl} /$ levulinic acid DESs in this work, were 1:2, 1:1, 1:2, and 1:2, respectively, as is also indicated in Table S1 in the Supplementary Information section and shown in Fig. 1a-d. On the other hand, the cellulose crystallite (Fig. 1e-f) was modeled with the OPLS 2005 FF (Banks et al. 2005), which has demonstrated to be a reliable FF for the modelling of carbohydrates, (Stortz et al. 2009; Rabideau et al. 2013, 2014; Rabideau and Ismail 2015; Velioglu et al. 2014; Kubicki et al. 2018; Stalker et al. 2019) and recently validated in our previous work (Sánchez-Badillo et al. 2021). The geometric combining rule was applied for all mixed $\epsilon_{i j}$ and $\sigma_{i j}$ interactions along with a scaling factor of 0.5 for the 1-4 Lennard-Jones and the 1-4 electrostatic interactions.

\section{Molecular dynamics simulations details.}

All MD simulations were carried out with the GROMACS (2020.4) package (Abraham et al. 2015). The v-rescale (Bussi et al. 2007) thermostat and Berendsen (Berendsen et al. 1984) barostat were used to keep constant the temperature and the pressure at $300 \mathrm{~K}$ and $1 \mathrm{bar}$, respectively. The v-rescale and Berendsen algorithms have been successfully applied in the literature for the calculation of thermodynamic and transport properties of either DES or ILs through MD simulations (Doherty and Acevedo 2018; Doherty et al. 2018). A coupling time of 1 ps was used for both temperature and pressure. Newton's equations of motion were integrated with a time step $(\Delta t)$ value of $1 \mathrm{fs}$ by using the leap-frog algorithm. Periodic boundary conditions were used along with a cut-off value of $16 \dot{A}$ and $30 \dot{A}$ for the calculation of the non-bonded interactions for condensed and gas-phase systems, respectively. For the condensed systems, the long-range non-bonded interactions beyond the cut-off were calculated by using the Smooth Particle-Mesh-Ewald (Essmann et al. 1995). On the contrary, for the gas phase systems, the scheme cut-off was used instead. The LINCS algorithm (Hess et al. 1997) was employed to constraint all covalent hydrogen bonds. Equilibration and production runs were carried out for all the systems as indicated below.

Electronic density calculations were carried out in order to reveal the HBs between cellulose unit cell and DES molecules. The electronic wave function of each system was obtained through density functional theory (DFT) calculations conducted in the TeraChem (Ufimtsev and Martínez 2008) software at the PBE0 (Perdew et al. 1996, 1997; Adamo and Barone 1999)/6-311g** level of theory with empirical dispersion corrections (Grimme et al. 2010). Then, the non-covalent interactions were obtained by analyzing the bond critical points of the electronic density $(\rho(\boldsymbol{r}))$ in the GPUAM (Hernández-Esparza et al. 2014, 2019; Cruz et al. 2019) package. Further details can be found in the Supplementary Information section. 

constructed using the Packmol package (Martínez et al. 2009). All DESs boxes were built in order to

191 provide similar box length sizes after the production stage. A minimization stage was performed by using

192 the steepest-descent method for 10000 steps in order to remove any possible steric clash. Then, the DESs

193 systems were equilibrated for $10 \mathrm{~ns}$ in the NPT ensemble at $300 \mathrm{~K}$ and $1 \mathrm{bar}$, and a production run for 15

194 ns was carried out at the same conditions. The cellulose I $\beta$ crystallite-DESs systems were constructed as 195 follows: a cellulose I $\beta$ crystallite of 39 glucan with a degree of polymerization (DP) of 12 each, see Fig. 1f, 196 was built using the cellulose-builder toolkit (Gomes and Skaf 2012). The constructed model implies the 197 current crystallographic standard for cellulose from Nishiyama et al. (2002). The cellulose crystallite was 198 placed in the center of a cubic box and then surrounded by the same number of DES molecules as in their 199 corresponding pure systems, see Table S1. A minimization stage of 10000 steps followed by $100 \mathrm{~ns}$ of 200 equilibration, and by a production run of $50 \mathrm{~ns}$ were carried out for all cellulose-DES systems in the NPT 201 ensemble at the same conditions as the pure state of DESs. Structural properties for both DES and 202 cellulose-DES systems were calculated from the production stages by using the TRAVIS software (Brehm 203 et al. 2020).

204

205

206 

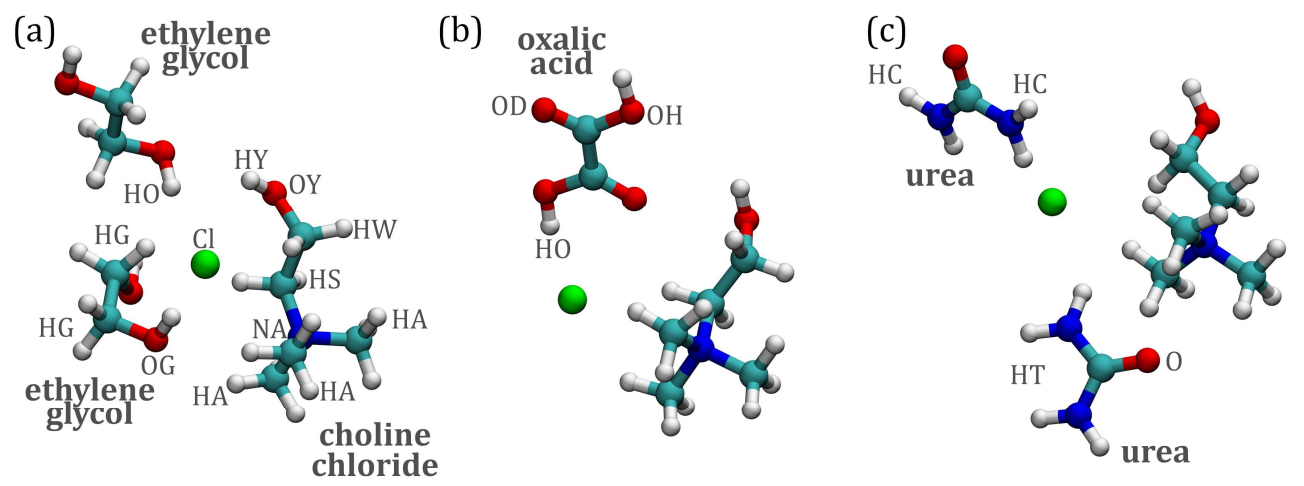

(d)

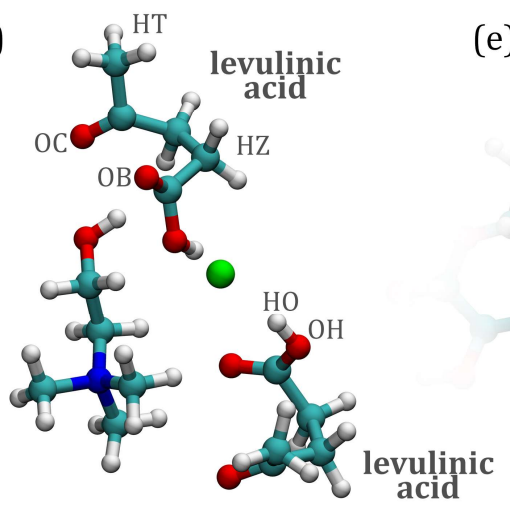

(e)

(f)
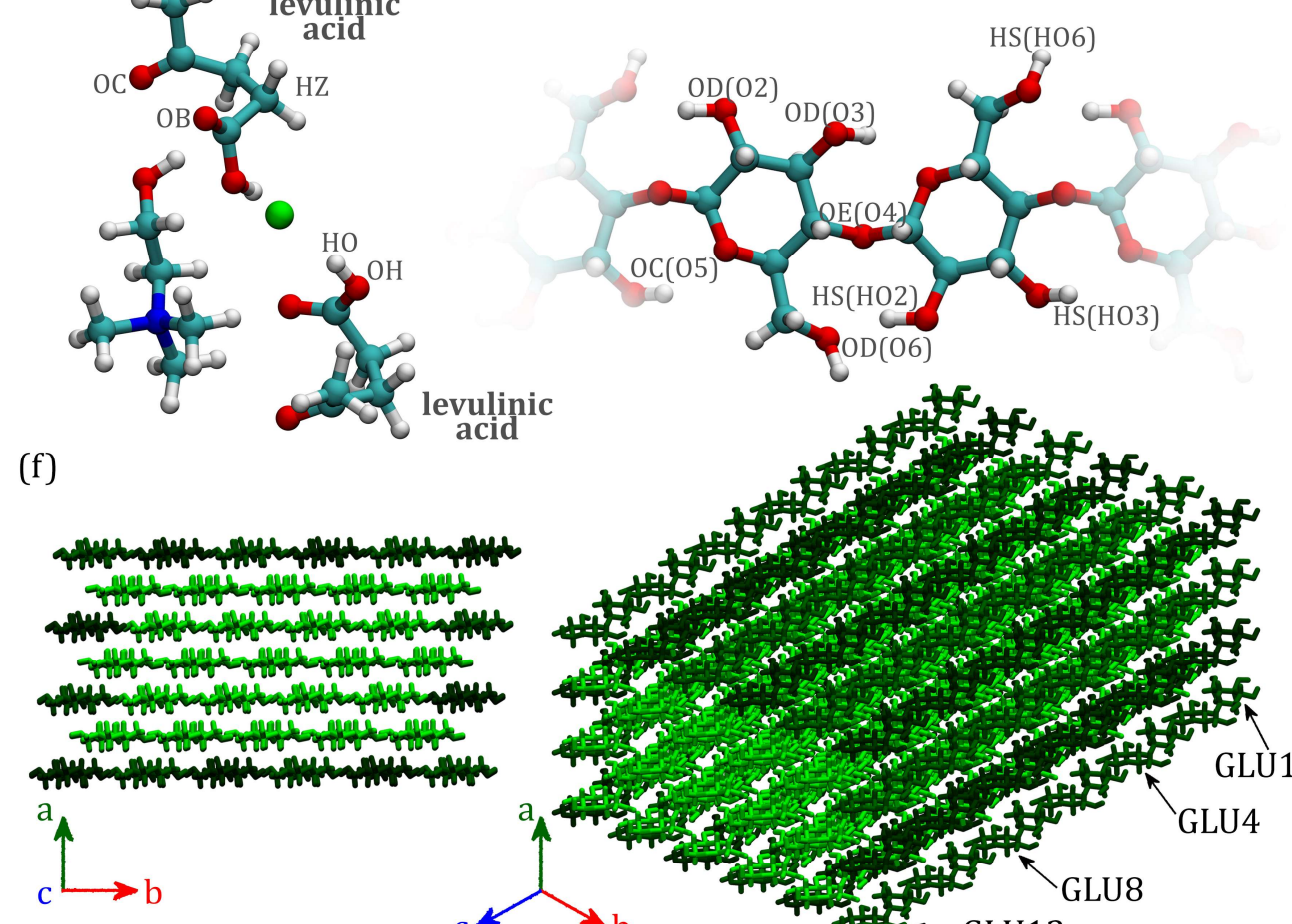

Fig. 1 Atomic labels and molecular structures for the deep eutectic solvents and cellulose crystallite modeled in this work. a Choline-chloride ethylene glycol (ChCl/ethylene glycol) with 1:2 HBA:HBD molar ratio. b Choline-chloride oxalic acid ( $\mathrm{ChCl} /$ oxalic acid, 1:1). c Choline-chloride urea (ChCl/urea, 1:2). d Choline-chloride levulinic acid ( $\mathrm{ChCl} /$ levulinic acid, 1:2). e Glucan atom labeling, including the commonly used atom numbering (in parenthesis); the OD atom label refers to the oxygen atom in the hydroxyl group, the OC atom label includes the oxygen atom within the six-member ring, and the HS atom label denotes the hydrogen atom attached to OD atom. $\mathbf{f}$ Cellulose crystallite composed by 39 glucan of 12 glucose units (GLU residues) each as indicated, arranged in seven layers; left: projection onto the a-b base plane, right: isometric projection. Glucan in these pictures have been green-scale colored for clarity. Color/atom code: blue/nitrogen, green/chlorine, grey/carbon, red/oxygen, and white/hydrogen. All images have been created with the visual molecular dynamics (VMD) software (Humphrey et al. 1996)

\section{Enthalpy of vaporization $\left(\Delta H_{v a p}\right)$.}

The enthalpy of vaporization for both DES and cellulose-DES systems was calculated by using the following equation (Liu et al. 2006; Zhong et al. 2011): 


$$
\Delta H_{\text {vap }}(T, P)=\left\langle E_{\text {pot, gas }}(T)\right\rangle-\frac{\left\langle E_{\text {pot }, \text { liq }}(T, P)\right\rangle}{N}+R T
$$

In Eq. (1) the $\left\langle E_{\text {pot,gas }}(T)\right\rangle$ and $\left\langle E_{\text {pot,liq }}(T, P)\right\rangle$ correspond to the average potential energy of gas and condensed phase, respectively; $N, R$, and $T$ are the total number of molecules in the liquid phase, the universal gas constant, and the temperature, respectively. Despite there is a lack of evidence regarding the composition of the gas phase for the studied DESs in this work (Ferreira et al. 2016; Salehi et al. 2019), results from MD calculations (Ferreira et al. 2016; Salehi et al. 2019) suggest that DES gas phase could be composed mainly by HBDs or by both HBDs and HBA:HBD DES clusters. In this work, the $\left\langle E_{\text {pot,gas }}(T)\right\rangle$ for the pure DES systems was calculated by using one HBA:HBD DES cluster as indicated in Table S1 and depicted in Fig. 1a-d. The DES cluster was placed into a large enough cubic box in order to avoid interactions with its images. Then, a run of 1000 steps for a minimization stage was developed, followed by an NVT equilibration run of $10 \mathrm{~ns}$ at $300 \mathrm{~K}$. The $\left\langle E_{\text {pot,gas }}(T)\right\rangle$ for cellulose-DES systems was calculated according to the literature (Liu et al. 2010), while the $\left\langle E_{p o t, l i q}(T, P)\right\rangle$ values for both DESs and celluloseDES systems were obtained from their corresponding production runs.

\section{Hildebrand solubility parameter ( $\delta)$.}

The solubility of one material in another is facilitated when their non-bond attractive forces are similar. Therefore, the dissolution capacity of a solvent regarding to a specific solute can be predicted if $\delta_{\text {solvent }} \sim \delta_{\text {solute }}$ (Rinaldi and Reece 2017). To explore this behavior in the pretreatment of cellulose by DESs, the $\delta$ parameters for the DESs were calculated through of the following equations (Liu et al. 2010):

$$
c=\frac{\left\langle E_{\text {pot }, \text { gas }}(T)\right\rangle-\frac{\left\langle E_{\text {pot }, \text { liq }}(T, P)\right\rangle}{N}}{V_{m}}=\frac{\Delta H_{\text {vap }}(T, P)-R T}{V_{m}}
$$

$$
\delta=\sqrt{c}
$$

Here $c$ is the cohesive energy density and $V_{m}$ the molar volume of the liquid phase.

\section{Results and discussions.}

DESs solvent behavior.

Density and molar volume. The calculated $\rho$ and $V_{m}$ for pure DES and cellulose-DES systems are shown in Table 1. It can be noticed that the calculated density of the DESs $\left(\rho_{\operatorname{sim}, D E S}\right)$ agreed with the available experimental density values, presenting an overall average deviation of $\sim 2.0 \%$. The addition of the cellulose crystallite (Fig. 1f and Fig. S2) into the DESs generated mixtures with an average mass cellulose composition of $\sim 16 \mathrm{wt} \%$ and larger density values than those for pure DESs. 
The effect of DES density in the cellulose pretreatment was explored through the relationship between calculated pure DES density and the $\beta$ parameter, as is shown in Fig. 2a. It is important to note that, to our knowledge, it was not found a complete set of experimental data for the $\beta$ and $\alpha$ parameters for the evaluated DESs in this work (Ren et al. 2016; Florindo et al. 2018). For this reason, the predicted Kamlet-Taft parameters values from ab-initio calculations by Kundu et al. (2020), were included. From Fig. 2a, a notable correlation emerged for the relationship between DESs density values and $\beta$ values, with a squared correlation coefficient $\left(R^{2}\right)$ of 0.91 . Similarly, from Fig. S3a the relation between DESs density values and $\alpha$ values also showed an important correlation $\left(R^{2}=0.84\right)$. Experimental evidence indicates that larger values of $\alpha$ and $\beta$ parameters are related to larger LCB dissolution (Ren et al. 2016; Liang et al. 2021). The correlations observed in Fig. 2a and S3a suggest that low-density DESs such as $\mathrm{ChCl} /$ ethylene glycol and $\mathrm{ChCl} /$ levulinic acid could provide a favorable environment for cellulose dissolution than high-density DESs such as $\mathrm{ChCl}$ /oxalic acid.

Häkkinen and Abbott (2019) indicated that the dissolution of cellulose is favored in some ILs due to their crystalline structure, since the addition of cellulose produces an increase in the entropy of the system. Therefore, larger entropy changes could conduct to large changes in densities from solvent upon the addition of solute. On this basis, the calculated density variations from pure DES to celluloseDES mixture $(\Delta \rho)$ are indicated in Table 1 , and their relationship with the Kamlet-Taft $\beta$ parameter is shown in Fig. $2 \mathrm{~b}$. It can be observed that the larger $\Delta \rho$ values $\left(\sim 0.053 \mathrm{~g} / \mathrm{cm}^{3}\right)$ correspond to the lowdensity DESs, including the $\mathrm{ChCl} /$ ethylene glycol, the $\mathrm{ChCl} /$ urea, and the $\mathrm{ChCl} /$ levulinic acid, with $\beta$ values of $0.57,0.5$, and 0.61 , respectively. A similar behavior can be found for the $\Delta \rho$ vs Kamlet-Taft $\alpha$ parameter correlation, shown in Fig. S3b.

In the same way than the $\rho$ and its change $\Delta \rho$ were studied, the molar volume and its change were also evaluated. As observed from Fig. 2c-d, the larger $V_{m}$ values are associated to the larger $\Delta V_{m}$ $\left(V_{m, \text { sim,cellulose-D }}-V_{m, \text { sim,DES }}\right)$ values, as indicated in Table 1 . However, both $V_{m}$ and $\Delta V_{m}$ displayed slight correlations with the Kamlet-Taft $\beta$ values $\left(R^{2}=0.66, R^{2}=0.62\right)$. Interestingly, the correlations between the $V_{m}$ and $\Delta V_{m}$ and the Kamlet-Taft $\alpha$ values were slightly better correlated $\left(R^{2}=0.75, R^{2}=\right.$ 0.71 ), as shown in Fig. S3c-d. The smallest $\Delta V_{m}$ (and $V_{m}$ ) values can be observed for the $\mathrm{ChCl} /$ oxalic acid DES for both cases. This behavior suggests that the small variations in the $V_{m}$ could produce repulsive interactions between solute and solvent that hinder the cellulose pretreatment in the DES bulk. Thus, bulk properties such as density and molar volume can be used as reference properties to identify new and sustainable solvents for cellulose pretreatment, avoiding the exhaustive traditional experimental measurements. 
291 Table 1 Calculated density and molar volume for DES and cellulose-DES systems at $300 \mathrm{~K}$ and 1 bar

\begin{tabular}{|c|c|c|c|c|c|c|c|c|c|}
\hline System & $\begin{array}{c}x_{\text {Cellulose }}^{a} \\
\text { [wto] }\end{array}$ & $\begin{array}{c}\rho_{\text {sim }} \\
{\left[\mathrm{g} / \mathrm{cm}^{3}\right]}\end{array}$ & $\begin{array}{c}\rho_{\exp } \\
{\left[\mathrm{g} / \mathrm{cm}^{3}\right]}\end{array}$ & \%errorb & $\begin{array}{c}V_{m, \text { sim }} \\
{\left[\mathrm{cm}^{3} / \mathrm{mol}\right]}\end{array}$ & $\begin{array}{c}\Delta \rho^{c} \\
{\left[\mathrm{~g} / \mathrm{cm}^{3}\right]}\end{array}$ & $\begin{array}{c}\Delta V_{m}{ }^{c} \\
{\left[\mathrm{~cm}^{3} / \mathrm{mol}\right]}\end{array}$ & $\begin{array}{c}\alpha \\
\text { (Kundu et } \\
\text { al. 2020) } \\
\end{array}$ & $\beta$ \\
\hline ChCl/ethylene glycol & & $1.1078 \pm 0.0018$ & $\begin{array}{l}1.1131 \text { (Yadav et al. 2015) } \\
\text { 1.1146 (Shahbaz et al. 2012)d } \\
1.116 \text { (Leron et al. 2012) } \\
1.115 \text { (Lapeña et al. 2019) }\end{array}$ & $\begin{array}{l}-0.48 \\
-0.61 \\
-0.73 \\
-0.65\end{array}$ & 238.09 & 0.0569 & 33.37 & 1.4732 & $\begin{array}{l}0.5694 \text { (Kundu } \\
\text { et al. } 2020 ; \\
\text { Florindo et al. } \\
\text { 2018) }\end{array}$ \\
\hline Cellulose-ChCl/ethylene glycol & 16.64 & $1.1647 \pm 0.0017$ & & & 271.47 & & & & \\
\hline $\mathrm{ChCl} /$ oxalic acid & & $1.2354 \pm 0.0012$ & $\begin{array}{l}1.2575 \text { (Florindo et al. 2014) } \\
1.282 \text { (Gontrani et al. 2018) }\end{array}$ & $\begin{array}{l}-1.76 \\
-3.63\end{array}$ & 185.9 & 0.0383 & 26.2 & 1.1921 & $\begin{array}{l}0.2707 \text { (Kundu et } \\
\text { al. 2020) }\end{array}$ \\
\hline Cellulose-ChCl/oxalic acid & 15.03 & $1.2737 \pm 0.0009$ & & & 212.09 & & & & \\
\hline $\mathrm{ChCl} /$ urea & & $1.1487 \pm 0.001$ & $\begin{array}{c}1.1963 \text { (Yadav and Pandey } \\
\text { 2014) } \\
\text { 1.1969 (Xie et al. 2014; } \\
\text { Chemat et al. 2016; Leron and } \\
\text { Li, 2012) } \\
\text { 1.1964 (Shekaari et al. 2017) }\end{array}$ & $\begin{array}{r}-3.98 \\
-4.03 \\
-3.99\end{array}$ & 226.11 & 0.0501 & 30.64 & 1.4176 & $\begin{array}{c}0.5 \text { (Kundu et al. } \\
\text { 2020; Florindo et } \\
\text { al. 2018) } \\
0.821 \text { (Ren et al. } \\
\text { 2016) }\end{array}$ \\
\hline Cellulose-ChCl/urea & 15.67 & $1.1988 \pm 0.001$ & & & 256.76 & & & & \\
\hline $\mathrm{ChCl} /$ levulinic acid & & $1.1342 \pm 0.0013$ & 1.1365 (Florindo et al. 2014) & -0.2 & 327.86 & 0.0516 & 46.77 & 1.5529 & $\begin{array}{c}0.6102 \text { (Kundu et } \\
\text { al. 2020) } \\
0.57 \text { (Florindo et } \\
\text { al. 2018) } \\
\end{array}$ \\
\hline Cellulose-ChCl/levulinic acid & 16.37 & $1.1858 \pm 0.0014$ & & & 374.63 & & & & \\
\hline
\end{tabular}

\begin{tabular}{|c|c|}
\hline $2 \overline{92}$ & ${ }^{a}$ Calculated as $x_{\text {cellulose }}=\frac{\text { cellulose mass }}{\text { total mass of solution }} \times 100$. \\
\hline 293 & ${ }^{b}$ Calculated as \%error $=\frac{\left(\rho_{\text {sim }}-\rho_{\text {exp }}\right)}{\left.\rho_{\text {ex }}\right)} \times 100$ for each experimental value. \\
\hline $\begin{array}{l}294 \\
295 \\
296\end{array}$ & $\begin{array}{l}{ }^{c} \text { Change in the thermodynamic property }(p) \text {, calculated as } \Delta p=p_{\text {sim, cellulose }-D E S}-p_{\text {sim, DES }} \text {. } \\
{ }^{d} \text { At } 303.15 \mathrm{~K} \text {. } \\
{ }^{\circ} \text { At } 298.15 \mathrm{~K} \text {. }\end{array}$ \\
\hline
\end{tabular}

297

298

299

300

301

302 
305 Table 2 Calculated enthalpy of vaporization, cohesive energy density, and Hildebrand parameter for DES and cellulose-DES systems at $300 \mathrm{~K}$ and 1 bar

\begin{tabular}{|c|c|c|c|c|c|c|c|c|c|}
\hline System & $\begin{array}{c}\Delta H_{\text {vap,sim }} \\
{[\mathrm{kcal} / \mathrm{mol}]}\end{array}$ & $\begin{array}{c}\Delta H_{\text {vap,sim,lit }}{ }^{a} \\
{[\mathrm{kcal} / \mathrm{mol}]}\end{array}$ & $\begin{array}{l}\Delta H_{\text {vap,exp }}{ }^{b} \\
{[\mathrm{kcal} / \mathrm{mol}]}\end{array}$ & $\begin{array}{c}c_{\operatorname{sim}} \\
{\left[\mathrm{cal} / \mathrm{cm}^{3}\right]}\end{array}$ & $\underset{\left[\mathrm{MPa}^{0.5}\right]}{\delta_{\text {sim }}}$ & $\begin{array}{l}\delta_{\text {sim }, l i t}{ }^{a} \\
{\left[\mathrm{MPa}^{0.5}\right]}\end{array}$ & $\begin{array}{l}\Delta \Delta H_{\text {vap, sim }}{ }^{c} \\
{[\mathrm{kcal} / \mathrm{mol}]}\end{array}$ & $\begin{array}{c}\Delta c_{\operatorname{sim}^{c}} \\
{\left[\mathrm{cal} / \mathrm{cm}^{3}\right]}\end{array}$ & $\begin{array}{c}E_{p o t, l i q} \\
{[\mathrm{kcal} / \mathrm{mol}]}\end{array}$ \\
\hline $\mathrm{ChCl} /$ ethylene glycol & $49.00 \pm 2.02$ & $\begin{array}{c}40.03 \pm 0.07 \text { (Ferreira et } \\
\text { al. } 2016)^{d} \\
31.96 \pm 0.05 \text { (Ferreira et }^{\text {al. } 2016)^{e}} \\
48.76 \text { (Salehi et al. 2019) }^{d} \\
17.45 \text { (Salehi et al. 2019) }^{e}\end{array}$ & $\begin{array}{l}\text { 13.34 (Ravula } \\
\text { et al. 2019) }\end{array}$ & 203.3 & 29.17 & $\begin{array}{l}29.3 \text { (Salehi } \\
\text { et al. 2019) } \\
24.5(\text { Salehi } \\
\text { et al. 2019)e }\end{array}$ & \multirow[t]{2}{*}{5.53} & \multirow[t]{2}{*}{-4.62} & $-81076 \pm 227$ \\
\hline Cellulose-ChCl/ethylene glycol & $54.53 \pm 1.92$ & & & 198.68 & & & & & $-76741 \pm 248$ \\
\hline \multirow{2}{*}{$\begin{array}{l}\text { ChCl/oxalic acid } \\
\text { Cellulose-ChCl/oxalic acid }\end{array}$} & $53.17 \pm 1.45$ & 51.86 (Salehi et al. 2019) $^{d}$ & & 282.81 & 34.4 & & \multirow{2}{*}{4.03} & \multirow{2}{*}{-15.69} & $-142880 \pm 120$ \\
\hline & $57.25 \pm 1.47$ & & & 267.12 & & & & & $-138304 \pm 105$ \\
\hline $\mathrm{ChCl} /$ urea & $54.72 \pm 3.07$ & $\begin{array}{l}54.49 \text { (Salehi et al. 2019) } \\
19.60 \text { (Salehi et al. 2019) }^{e} \\
48.04 \text { (Salehi et al. 2019) } \\
25.57 \text { (Salehi et al. 2019) }\end{array}$ & $\begin{array}{l}18.88 \text { (Ravula } \\
\text { et al. 2019) } \\
11.2 \text { (Shahbaz } \\
\text { et al. 2016) }\end{array}$ & 239.37 & 31.65 & $\begin{array}{l}31.6 \text { (Salehi } \\
\text { et al. 2019) } \\
26.5 \text { (Salehi }^{d} \\
\text { et al. 2019)e } \\
30.5 \text { (Salehi } \\
\text { et al. 2019) }{ }^{d} \\
31.2 \text { (Salehi } \\
\text { et al. 2019)e }\end{array}$ & \multirow[t]{2}{*}{4.94} & \multirow[t]{2}{*}{-9.33} & $-51357 \pm 130$ \\
\hline Cellulose-ChCl/urea & $59.66 \pm 2.94$ & & & 230.04 & & & & & $-47012 \pm 140$ \\
\hline \multirow{2}{*}{$\begin{array}{l}\text { ChCl/levulinic acid } \\
\text { Cellulose-ChCl/levulinic acid }\end{array}$} & $53.59 \pm 2.46$ & & & 161.64 & 26.01 & & \multirow{2}{*}{7.29} & \multirow{2}{*}{-0.72} & $-147303 \pm 163$ \\
\hline & $60.88 \pm 2.39$ & & & 160.92 & & & & & $-142843 \pm 151$ \\
\hline
\end{tabular}

$306 \quad{ }^{a}$ At $298.15 \mathrm{~K}$.

$308{ }^{c}$ Change in the thermodynamic property $(p)$, calculated as $\Delta p=p_{\text {sim, cellulose-DES }}-p_{\text {sim,DES }}$.

$309{ }^{d}$ Reported values in the literature by means of MD simulations, suggesting the DES cluster as the gas phase composition.

$310{ }^{e}$ Reported values in the literature by means of MD simulations, suggesting the HBD as the gas phase composition. 
(a)

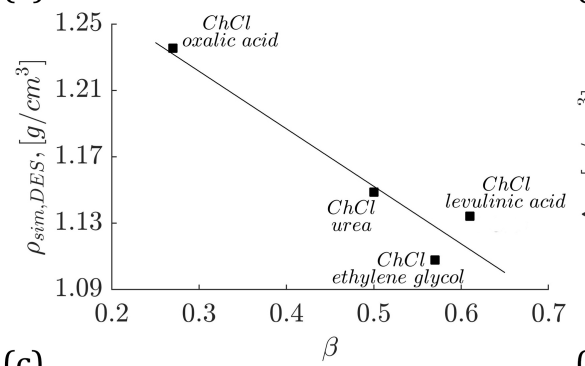

(c)

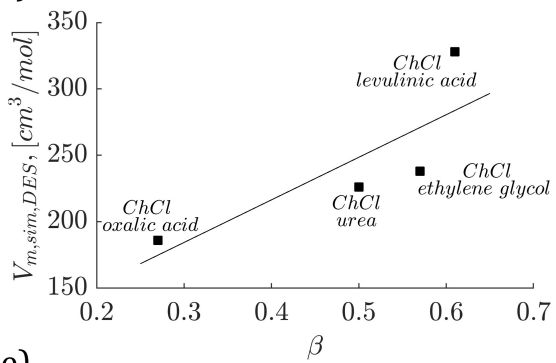

(e)

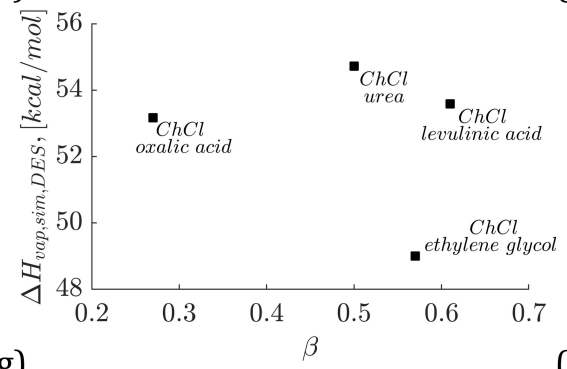

(g)

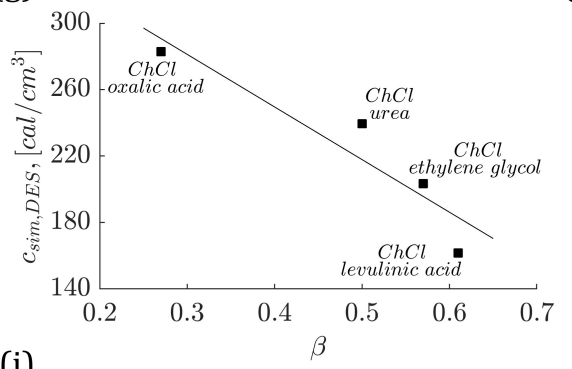

(i)

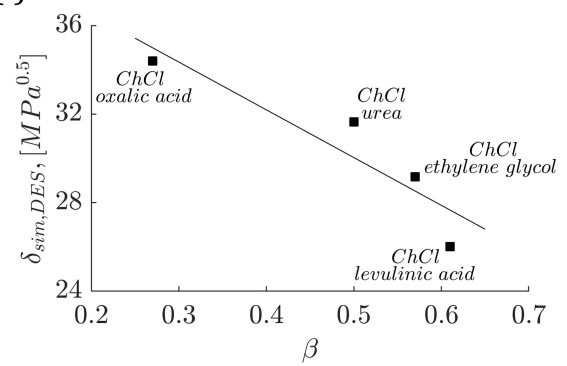

(b)

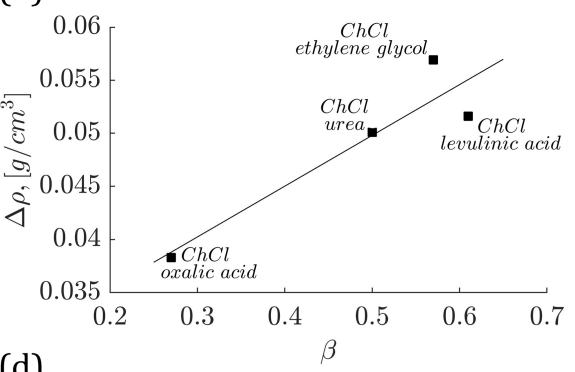

(d)

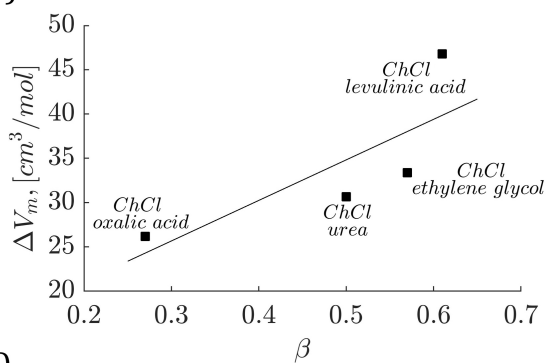

(f)

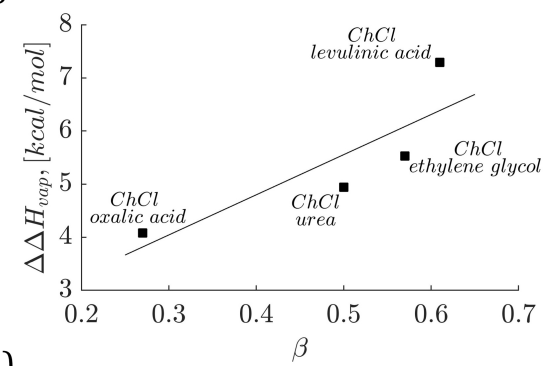

(h)

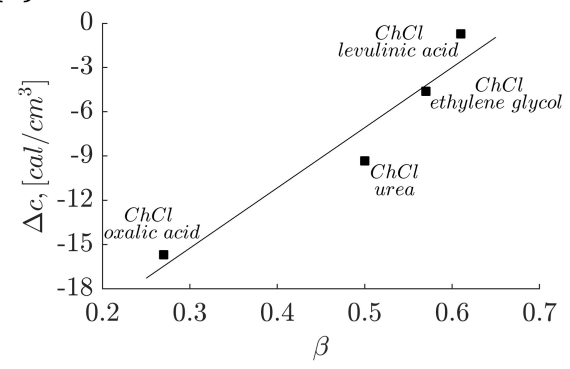

Fig. 2 Linear correlations observed between the Kamlet-Taft $\beta$ parameter and: a Density $\left(\rho_{\text {sim,solvent }}, R^{2}=0.91\right)$, b Density change $\left(\Delta \rho, R^{2}=0.86\right)$, c Molar volume $\left(V_{m, s i m}, R^{2}=0.66\right)$, d Molar volume change $\left(\Delta V_{m}, R^{2}=0.61\right)$, e Enthalpy of vaporization $\left(\Delta H_{\text {vap,sim }}, R^{2}=0.06\right)$, $\mathbf{f}$ Enthalpy of vaporization change $\left(\Delta \Delta H_{v a p}, R^{2}=0.72\right)$, $\mathbf{g}$ Cohesive energy density $\left(c_{\text {sim }}, R^{2}=0.87\right)$, h Cohesive energy density change $\left(\Delta c, R^{2}=0.93\right)$, and i Hildebrand parameter $(\delta$, $\left.R^{2}=0.84\right)$ 
321 Enthalpy of vaporization. Results for the energetic thermodynamic properties of the bulk, including

$322 \Delta H_{\text {vap }}, c$, and $\delta$ obtained for both DES and cellulose-DES systems through eq 1-3, are displayed in Table

3232 . The calculated enthalpy of vaporization $\left(\Delta H_{v a p, \text { sim }}\right)$ values agreed with MD estimated values reported

324 in the literature $\left(\Delta H_{v a p, s i m, l i t}\right)$ which also assumed the same composition of the gas phase (Salehi et al.

325 2019). However, the $\Delta H_{\text {vap,sim }}$ values displayed a significant deviation respect to those calculated from

326 experimental properties (Shahbaz et al. 2016; Ravula et al. 2019). This was to be expected, since more

327 information is needed regarding the composition of the DESs in gas phase (Ferreira et al. 2016; Salehi et

328 al. 2019).

329 The relationship between the $\Delta H_{\text {vap,sim }}$ and the $\beta$ and $\alpha$ parameters revealed no correlation, due

330 to $R^{2}=0.06$, and $R^{2}=0.03$ as displayed in Fig. 2 e and Fig. S3e, respectively. Interestingly, the addition

331 of the cellulose crystallite into the bulk of the DESs produced positive enthalpy of vaporization changes

$332\left(\Delta \Delta H_{v a p} \sim 5.5 \mathrm{kcal} / \mathrm{mol}\right)$, as consequence of the $E_{\text {pot,liq }}$ reduction (repulsion interactions) of the mixture

333 compared with the pure system, as it can be noticed in the Table 2. Surprisingly, after the cellulose

334 crystallite addition, the correlation between the $\Delta \Delta H_{\text {vap }}$ and the Kamlet-Taft $\beta$ values increased up to

$335 R^{2}=0.72$ (Fig. 2f), and $R^{2}=0.80$ for the Kamlet-Taft $\alpha$ parameter (Fig. S3f). This was probably related

336 to the absence of strong attractive interactions between cellulose crystallite and DES molecules, thus

337 favoring the repulsion interactions with the bulk of the DES and the gas phase formation. Accordingly,

338 the energy required to achieve the gas phase upon the addition of the cellulose crystallite could be

339 smaller than those in pure DESs where attractive interactions are larger. In other words, the larger

$340 \quad$ Kamlet-Taft $\beta$ and $\alpha$ values the larger $\Delta \Delta H_{\text {vap }}$ for the evaluated DESs.

341

342

343

Cohesive energy density. Tang et al. (2017) indicated that, despite both 1-butyl-3-methylimidazolium chloride $\left(\left[\mathrm{C}_{4} \mathrm{mim}\right][\mathrm{Cl}]\right)$ IL and $\mathrm{ChCl}$-based DESs are composed by chloride anions, the largely reduced activity of the $\mathrm{Cl}^{-}$ion within the DESs was probably related to the restricted HB network. The above despite that the Kamlet-Taft $\beta$ parameter (proton accepting) of the $\left[\mathrm{C}_{4} \mathrm{mim}\right][\mathrm{Cl}] \mathrm{IL}$ is larger $(\beta=0.94$ (Lungwitz and Spange 2008)) than, for example, the $\mathrm{ChCl} /$ levulinic acid DES ( $\beta=0.61$ (Kundu et al. 2020)). Thus, it seems reasonable that low $c$ values might provide a favorable media to dissolve or pretreat the cellulose.

The calculated values for the $c$ of both DESs and cellulose-DES systems are indicated in Table 2,

$351 \beta$ and $\alpha$ values are shown in Fig. 2g and Fig. S3g, respectively. As it can be observed, there was a suitable 352 correlation between cohesiveness and the Kamlet-Taft parameters $\left(R^{2}=0.87\right.$ and 0.91 for $\beta$ and $\alpha$, 353 respectively). This could be explained since the $c$ is a direct measure of the strength of the intermolecular 354 forces. Thus as $c$ becomes larger, the favorable solute-solvent interactions are hindering due to the 355 strength of the solvent-solvent interactions. Similar highlights have suggested from García et al. (2015) 356 comparing DESs compressibility experimental values. 
Interestingly, the relationship between $\Delta c$ values and Kamlet-Taft $(\beta$ or $\alpha$ ) parameters correlated better $\left(R^{2}=0.93\right.$ for $\beta$ in Fig. $2 \mathrm{~h}$ and $R^{2}=0.95$ for $\alpha$ in Fig. S3h), than the relationship $c$ values vs Kamlet-Taft parameters $\left(R^{2}=0.87\right.$ for $\beta$ and $R^{2}=0.91$ for $\left.\alpha\right)$. This was to be expected since $\Delta c$ involved the reduction of the $E_{\text {pot,liq }}$ (shown in Table 2) in the cellulose-DES mixture, as reported for the

$361 \Delta \Delta H_{\text {vap,sim,DES }}$. From Fig. $2 \mathrm{~h}$ and Fig. S3h, it can be noted that the (absolute) small $\Delta c$ values corresponded

362 to the DESs with larger both Kamlet-Taft $\beta$ and $\alpha$ values. This suggest the formation of attractive 363 interactions between solute and solvent at same time the solvent maintains its own interactions. This is 364 in accordance with the findings of Häkkinen and Abbott (2019) who evaluated the interactions between glucose and $\mathrm{ChCl} /$ ethylene glycol DES. They found that DES was able to maintain its interactions with itself as the same time the $\mathrm{ChCl}$ and ethylene glycol HBD were able to form new HBs with glucose.

Hildebrand parameter. The Hildebrand parameter $(\delta)$ is a key property to select solvents for separation process (Salehi et al. 2019). As it can be noted from Table 2, the calculated Hildebrand parameter $\left(\delta_{\text {sim,DES }}\right)$ values agreed with those reported by Salehi et al. $(2019)$ by using the HBA:HBD DES cluster as the component of the gas phase. Furthermore, by analyzing the $\delta_{\text {sim,lit }}$ set, it can be observed that the average of the $\delta_{C h C}$ /ethylene glycol is larger than the average of the $\delta_{C h C l / u r e a}$ value, in qualitative agreement with the $\delta_{\text {sim,DES }}$ calculated in this work. Despite the $\delta$ values can be estimated through the reported vapor pressure ( $p_{v a p}$ ) data from Shahbaz et al. (2016), Salehi et at. (2019) indicated that the units of the enthalpies of vaporization (and thus $\delta$ ) remained unclear from experiments.

Rinaldi and Reece (2017) have summarized the available data regarding the experimental $\delta$ for cellulose $\left(\delta_{\text {cellulose }}\right)$. Unfortunately, the $\delta_{\text {cellulose }}$ experimental values presented large variation between them, since they range from 25.7 up to $39.9 \mathrm{MPa}^{0.5}$, therefore a direct comparison with $\delta_{\text {sim,DES }}$ could provide unclear conclusions. Despite the DESs were not able to dissolve the cellulose crystallite under the evaluated conditions, it seems reasonable to suggest a possible relationship between $\delta_{\text {sim }}$ and Kamlet-Taft parameters for cellulose pretreatment for the tested DESs. The relationship between the $\delta_{\text {sim,DES }}$ with Kamlet-Taft parameters is shown in Fig. 2 i for $\beta$ parameter and in Fig. S3i for $\alpha$ parameter. Interestingly, both Kamlet-Taft values for the $\beta$ and $\alpha$ parameters, and the $\delta_{\text {sim,DES }}$ presented meaningful correlations $\left(R^{2}=0.84\right.$ and $R^{2}=0.89$, respectively), suggesting that DESs with small $\delta$ values are suitable to disrupt the cellulose crystallite.

It seems that the cellulose pretreatment ability of the DESs, described by the Kamlet-Taft parameters, can be correlated with a series of thermodynamic properties of the DESs (Fig. 2 and Fig. S3), as suggested Ren et al. (2016). However, the evaluation of the atomistic structure and energetics involving in the disruption of the cellulose crystallite might provide a more detailed description of the cellulose pretreatment or its disruption with DESs, as well as towards the Kamlet-Taft parameter values. The following section was focused to provide valuable atomistic information regarding the use of DESs as possible sustainable solvents for the cellulose pretreatment. 


\section{Cellulose crystallite disruption.}

Cellulose-DES radial distribution functions. Briefly, the RDF indicates the probability $g(r)$ that one particle finds another particle as a function of distance, $r$. The calculated cellulose-DES RDFs involved the interactions between OD, OC, and HS atoms from cellulose crystallite and the corresponding: HA, HW, $\mathrm{HS}_{\mathrm{D}}, \mathrm{HY}, \mathrm{HO}, \mathrm{HG}, \mathrm{HC}, \mathrm{HT}, \mathrm{Cl}, \mathrm{OY}, \mathrm{OG}, \mathrm{OH}, \mathrm{OD}$, $\mathrm{O}, \mathrm{OB}$, and $\mathrm{OC}_{\mathrm{D}}$ atoms from DES. The RDF plots are displayed in Fig. 3, Fig. S4, Fig. S5, and Fig. S6 for the cellulose- $\mathrm{ChCl}$ /ethylene glycol, cellulose-ChCl/oxalic acid, cellulose- $\mathrm{ChCl} / \mathrm{urea}$, and cellulose- $\mathrm{ChCl} / \mathrm{levulinic}$ acid systems, respectively. On the other hand, the HBAHBD RDFs involving the interactions between the $\mathrm{Cl}$ atom from HBA and the corresponding: $\mathrm{HY}, \mathrm{HO}, \mathrm{HC}$, and HT atoms from HBD, are displayed in Fig. S7 for the same cellulose-DES systems. For all the interactions, the first peak position and its corresponding coordination number $\left(N_{\text {coord }}\right)$, calculated by integrating the $g(r)$ until the first minimum, have also been summarized in Table 3. Additionally, the molecules are displayed in Fig. S8 to Fig. S11 for all the cellulose-DES systems.
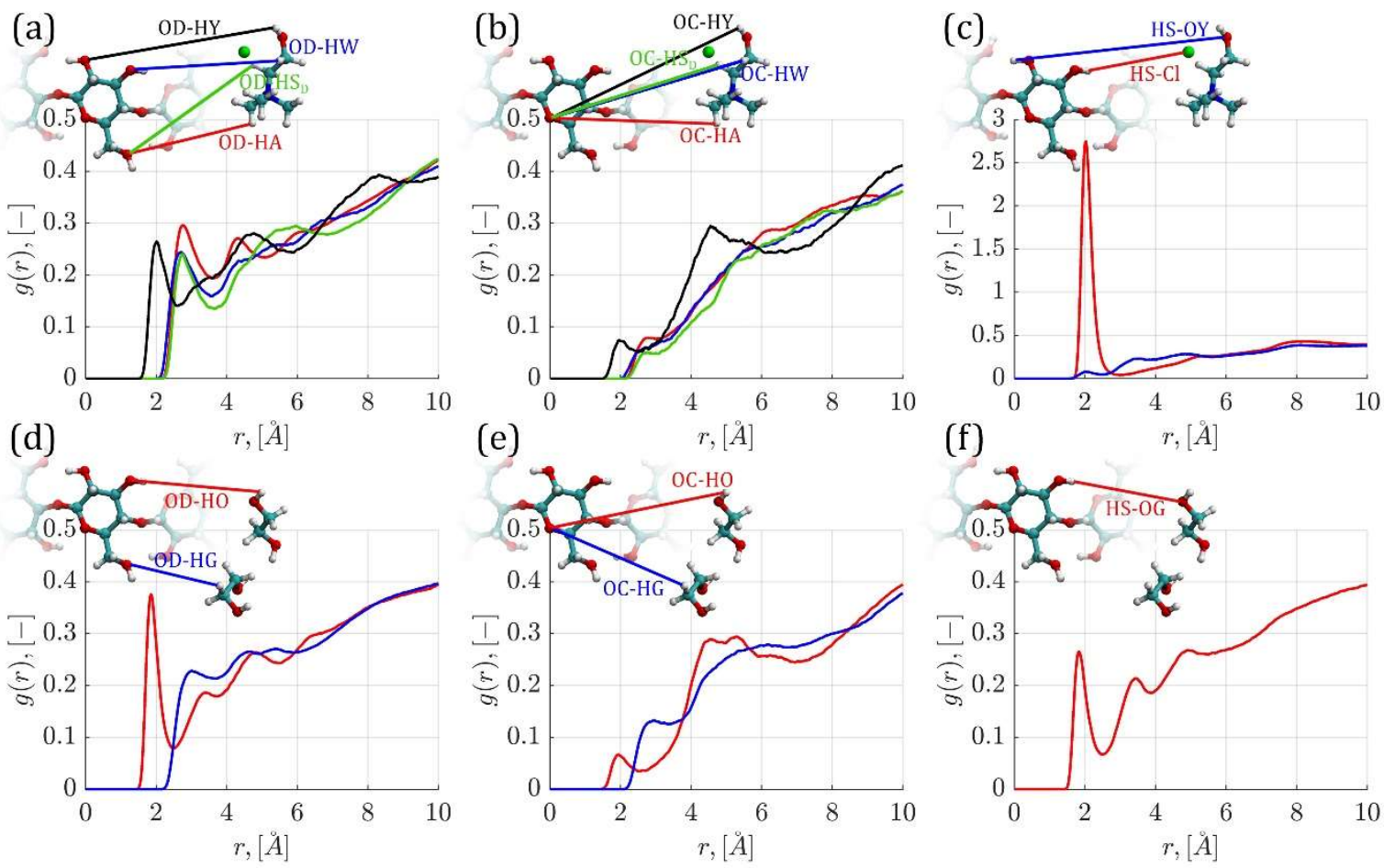

Fig. 3 RDFs for searching possible HBs between cellulose crystallite (OD, OC, and HS atoms) and ChCl/ethylene glycol (HA, HW, HS, HY, HO, HG, Cl, OY, and OG atoms) in the cellulose-ChCl/ethylene glycol system. The interactions involved: a OD oxygen atoms from glucose units and hydrogen atoms from choline cation. b OC oxygen atoms from glucose units and hydrogen atoms from choline cation. $\mathbf{c}$ HS hydrogen atoms from glucose units and OY oxygen atom from choline cation and chloride anion. $\mathbf{d}$ OD oxygen atoms from glucose units and hydrogen atoms from ethylene glycol HBD. e OC oxygen atoms from glucose units and hydrogen atoms from ethylene glycol HBD. f HS hydrogen atoms from glucose units and oxygen atoms from ethylene glycol HBD. Atomic labels are also shown in Fig. 1 
417 Table 3 First peak distance position $(\dot{A})$ and corresponding $N_{\text {coord }}$ (in parenthesis) for pair interactions 418 between cellulose and DESs, ${ }^{a}$ and between HBA and HBD in pure DESs and cellulose-DES systems Interactions between cellulose and DES.

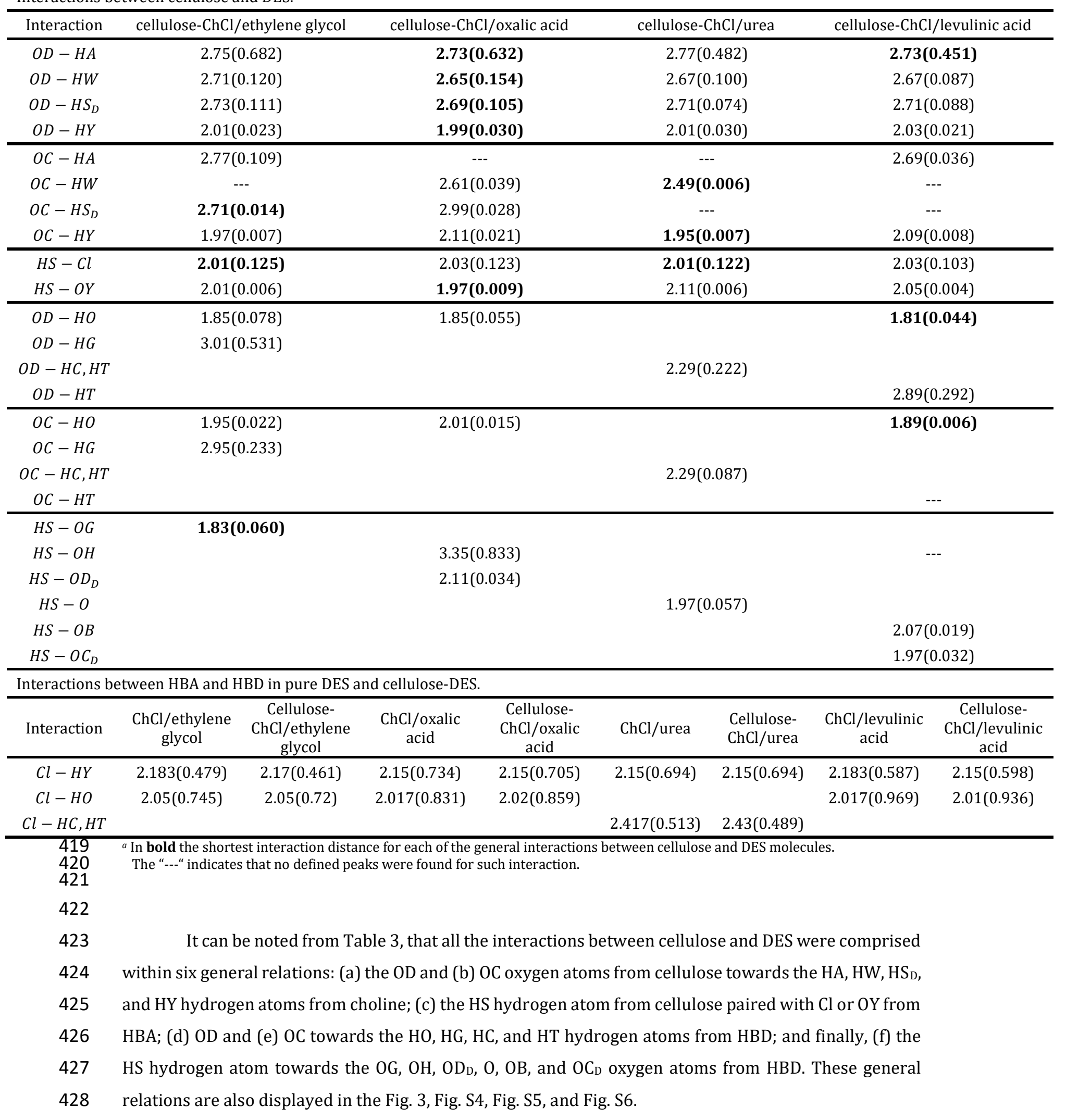


The $O D-H A, H W, H S_{D}$ interactions were located at similar distances $(\sim 2.7 \dot{A})$, whereas the $O D-H Y$ interaction was positioned at $\sim 2.01 \dot{A}$, as it is observed in Fig. 3a, S4a, S5a, and S6a. In a RDF analysis, a strong HB is generally related to a short interaction distance with a large and well-defined $g(r)$ peak (Doherty et al. 2018). Accordingly, not only the strongest $O D-H Y$ HBs were found in the cellulose- $\mathrm{ChCl} /$ oxalic acid system $(1.99 \dot{A})$, but also all the remaining HBs involving the $O D-$ $H A, H W, H S_{D}$ atoms, were stronger or more frequent than in the other DESs (see also Fig. S9). This might suggest that the cellulose crystallite presented favorable interactions towards the choline cation through HBs in the $\mathrm{ChCl}$ /oxalic acid DES, which is also indicated by the larger $N_{\text {coord }}$ shown in Table 3 (note that the small $N_{\text {coord }}$ values are due to absence of cellulose dissolution). This behavior could hinder other relevant and stronger cellulose-DES interactions such as those involving $\mathrm{Cl}^{-}$and the HBD. Interestingly, the remaining cellulose-DES systems (which have larger Kamlet-Taft $\beta$ values) showed weaker $O D-$ $H Y, H A, H W, H S_{D}$ interactions. These results may explain the smallest $\Delta \Delta H_{\text {vap }}$ and the largest change in the cohesiveness of the cellulose-DES mixture reported in Table 2 for the $\mathrm{ChCl} /$ oxalic acid DES.

Interactions involving the $O C-H A, H W, H S_{D}$ were less frequent than those involving the OD oxygen atom, as is shown in Fig. 3b and in Fig. S4b, S5b, S6b. This is probably caused by a steric effect surrounded the OC atom within the glucose unit. Despite the $O C-H A, H W, H S_{D}, H Y$ interactions play a minor role due to the larger position and non-well-defined of their initial peaks, the shortest interaction distances corresponded to the $O C-H Y$ HBs.

From Fig. 3c, S4c, S5c, and S6c, the $\mathrm{HS}-\mathrm{Cl}$ interaction was located at around of $2.02 \dot{A}$ for all cellulose-DES systems (see also Fig. S8b, S9b, S10b, and S10b). This HB was the most prominent and thus frequent interaction due to its large $g(r)$ value, in agreement with the findings of Häkkinen and Abbott (2019). However, other interactions involving the HS hydrogen atom are positioned at shorter distances. For example, the $H S-O G$ in the cellulose- $\mathrm{ChCl} /$ ethylene glycol system (Fig. 3f), is located at $1.83 \dot{A}$, and the $H S-O$ in the cellulose- $\mathrm{ChCl} /$ urea system at $1.97 \dot{A}$ (Fig. S5f), as it was reported in the literature (Smirnov et al. 2020). It can be noted from Table 3, that shorter $\mathrm{HS}-\mathrm{Cl}$ distances occurred in DESs with relatively large Kamlet-Taft $\beta$ and $\alpha$ values (2.01 $\dot{A}$ in the $\mathrm{ChCl} /$ ethylene glycol and $\mathrm{ChCl} /$ urea DESs), however the distances were slightly larger for $\mathrm{ChCl}$ /oxalic acid and $\mathrm{ChCl} /$ levulinic acid DESs. Recently, some authors (Chen et al. 2019; Zhang et al. 2020) have suggested that the presence of strong HB network within the solvent hinders its interaction with cellulose, making difficult either its pretreatment or dissolution. On this regard, the main interactions between HBA and HBD within the DES were also calculated and shown in Table 3. It can be noticed that the smallest $\mathrm{Cl}-H Y$ distances for pure DESs (displayed also in Fig. S7a, S7c, S7e, and S7g) are present in $\mathrm{ChCl}$ /oxalic acid and $\mathrm{ChCl} /$ urea. Furthermore, the $\mathrm{Cl}-\mathrm{HY}$ in the $\mathrm{ChCl} /$ oxalic acid DES also displayed the largest $N_{\text {coord }}(0.734)$. The small $\mathrm{Cl}-\mathrm{HY}$ the DES. 
It was observed in Table 3 that the first peak for the $\mathrm{Cl}-\mathrm{HY}$ interaction, decreases its height for the most of the evaluated DESs upon the addition of the cellulose crystallite, contrary to what was found in the $\mathrm{ChCl} /$ oxalic acid DES, which remained constant. This reduction of the $\mathrm{Cl}-\mathrm{HY} \mathrm{HB}$ distance might explain the small $\Delta c$ values calculated for the $\mathrm{ChCl} /$ ethylene glycol, $\mathrm{ChCl} /$ urea, and $\mathrm{ChCl} /$ levulinic acid DESs. Meanwhile, the largest $\Delta c$ value for the $\mathrm{ChCl} /$ oxalic acid DES can be associated to the null change in the $C l-H Y$ distance.

The $H S-O Y$ interactions in Fig. 3c, S4c, S5c, and S6c seems to be correlated with the $O D-H Y$ interactions, due to small $O D-H Y$ distances promote a closer interaction between their bonded atoms: HS and OY, respectively. For example, the smallest $O D-H Y$ distance was found in the cellulose$\mathrm{ChCl} /$ oxalic acid system, consequently, the smallest $H S-O Y$ distance was also found in such DES. These findings and those related for the $O D-H A, H W, H S_{D}, H Y$, suggest that DESs with smaller Kamlet-Taft $\alpha$ and $\beta$ values presented larger interactions between cellulose and choline cation.

Interactions involving the OD and hydrogen atoms from HBD are displayed in Fig. 3d, Fig. S4d, S5d, and S6d. These figures display the distances between the OD and the hydrogen atoms from the hydroxyl moieties in the HBD (HO). As it can be noted, these interactions show higher $g(r)$ peaks than those related to the $H A, H W, H S_{D}, H Y$ hydrogen atoms in the choline cation (Fig. 3a, S4a, S5a, S6a). Accordingly, the $O D-H O$ HBs play a more relevant role towards the cellulose crystallite disruption than the $O D-H A, H W, H S_{D}, H Y$ HBs. This ability to form stronger hydrogen bonds of the HBD towards the OD atoms, i.e. the hydrogen bond acidity capacity, measured through the Kamlet-Taft $\alpha$ parameter (Dwamena and Raynie 2020; Kundu et al. 2020), could be explained from the interactions between $\mathrm{Cl}^{-}$ and the $\mathrm{HO}$ atoms (Fig. S7b, S7d, S7f, and S7h). On this line, large $\mathrm{Cl}-\mathrm{HO}$ interaction distances (weak HBs) within the DES might enhance the formation of $\mathrm{HBs}$ with solute, such as in the $\mathrm{ChCl} / \mathrm{ethylene}$ glycol DES, contrary to the stronger $\mathrm{Cl}-\mathrm{HO} \mathrm{HBs}$ present in $\mathrm{ChCl} /$ oxalic acid and $\mathrm{ChCl} /$ levulinic acid DESs. Interestingly, the larger interaction distance between $\mathrm{Cl}^{-}$anion and hydrogen atoms from HBD was found for the $\mathrm{Cl}-\mathrm{HC}, \mathrm{HT} \mathrm{HB}$ present in $\mathrm{ChCl} /$ urea DES (Table 4 and Fig. S7f). The shortest $O D-H O$ distance was found for the cellulose-ChCl/levulinic acid system, in agreement with its larger Kamlet-Taft $\alpha$ parameter (1.55 (Kundu et al. 2020)). Finally, from the RDFs analysis, the HBs involving the OD and the $\mathrm{HG}$ atoms in $\mathrm{ChCl} /$ ethylene glycol (Fig. 3d) and the $\mathrm{HT}$ atom in $\mathrm{ChCl} /$ levulinic acid (Fig. S6d) DESs, presented the largest interactions distances and displayed the smallest $g(r)$ values.

The $O C-H O$ interactions (including the $O C-H C, H T$ in the cellulose-ChCl/urea) are shown in Fig. 3e, Fig. S4e, S5e, and S6e. The $O C-H O$ interactions showed similar behavior than the $O C-$ $H A, H W, H S_{D}, H Y$ HBs. From Table 3, the behavior of the $O C-H O \mathrm{HB}$ becomes stronger in the following order: $\mathrm{ChCl} /$ oxalic acid $<\mathrm{ChCl} /$ ethylene glycol $<\mathrm{ChCl} /$ levulinic acid, because its corresponding distance decreases as $2.01>1.95>1.81 \dot{A}$. These behavior agrees with the corresponding Kamlet-Taft $\beta$ values $(0.27,0.57$, and 0.61 , respectively), and Kamlet-Taft $\alpha$ values $(1.19,1.47$, and 1.55) (Kundu et al. 2020). Regarding to the cellulose- $\mathrm{ChCl} /$ urea system, due to the absence of $\mathrm{OH}$ hydrogen atoms in the urea HBD, the $O C-H C, H T$ interactions in Fig. S5e presented the largest distances $(2.29 \dot{A})$. 
Finally, the interactions between HS and oxygen atoms from HBD are displayed in Fig. 3f, S4f, S5f, and S6f. As it can be observed, the stronger interactions were $H S-O G, H S-O$, and $H S-O C_{D}$, in cellulose-ChCl/ethylene glycol (Fig. 3f), cellulose-ChCl/urea (Fig. S5f), and cellulose-ChCl/levulinic (Fig. S6f) systems, respectively. Interestingly, the $\mathrm{OH}$ atom in the $-\mathrm{COOH}$ moiety present in $\mathrm{ChCl} /$ oxalic acid (Fig. S4f) and $\mathrm{ChCl/levulinic} \mathrm{acid} \mathrm{(Fig.} \mathrm{S6f)} \mathrm{DESs,} \mathrm{formed} \mathrm{the} \mathrm{weaker} \mathrm{interactions} \mathrm{with} \mathrm{the} \mathrm{HS} \mathrm{atom.} \mathrm{The}$ peaks of these interactions were located at larger distances or showed less occurrences, compared with the $H S-O G \mathrm{HB}$ in the cellulose- $\mathrm{ChCl} /$ ethylene glycol system (Fig. 3f), or even with the $H S-O C_{D}$ in the cellulose-ChCl/levulinic acid system. This suggests that stronger HS-oxygen interactions between cellulose and HBD, might be enhanced for R-CO-R structures within the HBD. However, in order to validate such an assumption, a larger number of HBD must be evaluated.

The largest $g(r)$ values present in the interactions between $\mathrm{HS}-\mathrm{Cl}$ (hydrogen bond basicity) and the relevant $O D-H O$ (hydrogen bond acidity), indicated that such HBs might play a significant role in the deformation or disruption of the cellulose crystallite. These processes are related with the weakening or the breaking of the inter- and intrachain HBs within the solute (Procentese et al. 2015) (van Osch et al. 2017; Chen et al. 2019). In order to explore this effect, the total (inter- and intrachain) HBs have been analyzed for all cellulose-DES systems.

HBs within the cellulose crystallite. The disruption of the inter- and intrachain HBs must be a key step towards the understanding of the cellulose pretreatment with DESs (Procentese et al. 2015). The total interchain and intrachain number of HBs within the cellulose crystallite has been plotted as function of the last 50 ns of simulation (production time) and displayed in Fig. S12. The number of HBs formed between the cellulose crystallite and choline cation (HBs cellulose-ch ), chloride anion $\left(H B s_{\text {cellulose-chloride }}\right)$, and HBD $\left(H B s_{\text {cellulose-HBD }}\right)$, was also obtained and indicated in Table 4. All the HBs in this analysis have been calculated through the Hydrogen Bonds plugin available in the VMD program (Humphrey et al. 1996), which involves a donor-acceptor (D-A) distance less than $3.5 \dot{A}$ and an acceptor-donor-hydrogen (A-D-H) angle less than $30^{\circ}$ (Li et al. 2015). 
543 Table 4 Calculated number of HBs and molecular properties of the cellulose crystallite in DES at $300 \mathrm{~K}$ 544 and 1 bar

\begin{tabular}{|c|c|c|c|c|c|c|c|c|}
\hline System & intrachain & interchain & $\begin{array}{l}\text { cellulose- } \\
\text { choline }\end{array}$ & $\begin{array}{c}\text { cellulose- } \\
\text { chloride }\end{array}$ & $\begin{array}{l}\text { cellulose- } \\
\text { HBD }\end{array}$ & $\begin{array}{c}r_{\text {intrachain } H B s} \\
{[\mathrm{HBs} / \mathrm{ns}]}\end{array}$ & $\begin{array}{c}D_{\text {sim, cellulose }-D E S} \times 10^{10} \\
{\left[\mathrm{~cm}^{2} / \mathrm{s}\right]}\end{array}$ & $\begin{array}{c}E_{\text {non-bonded,cellulose }} \\
{[\mathrm{kcal} / \mathrm{mol}]} \\
\end{array}$ \\
\hline $\begin{array}{l}\text { cellulose- } \\
\mathrm{ChCl} / \text { ethylene glycol }\end{array}$ & $518 \pm 13$ & $476 \pm 16$ & $46 \pm 6$ & $161 \pm 8$ & $176 \pm 12$ & -0.403 & 8.380 & -6447.83 \\
\hline $\begin{array}{l}\text { cellulose- } \\
\mathrm{ChCl} / \text { oxalic acid }\end{array}$ & $540 \pm 12$ & $468 \pm 16$ & $59 \pm 7$ & $151 \pm 5$ & $92 \pm 7$ & -0.216 & 0.444 & -6660.10 \\
\hline $\begin{array}{l}\text { cellulose- } \\
\mathrm{ChCl} / \text { urea }\end{array}$ & $555 \pm 12$ & $454 \pm 16$ & $43 \pm 6$ & $155 \pm 5$ & $198 \pm 12$ & -0.277 & 0.369 & -6530.86 \\
\hline $\begin{array}{l}\text { cellulose- } \\
\text { ChCl/levulinic acid }\end{array}$ & $561 \pm 14$ & $468 \pm 16$ & $35 \pm 6$ & $126 \pm 6$ & $98 \pm 8$ & -0.514 & 1.543 & -6735.63 \\
\hline
\end{tabular}

545

546

547

548

549

550

551

552

553

554

555

556

557

558

559

560

561

562

563

564

565

566

567

568

569

570

571

572

573

From Fig. S12a and Fig. S12d, a reduction of the intrachain HBs can be observed for the $\mathrm{ChCl} /$ ethylene glycol and $\mathrm{ChCl} /$ levulinic acid DESs, contrary to the behavior shown in $\mathrm{ChCl}$ /oxalic acid and even ChCl/urea DESs (Fig. S12b and Fig. S12c). On the other hand, the number of the interchain HBs remained almost constant for all cellulose-DES systems along the production time. Furthermore, the interchain HBs were all similar to each other as indicated in the Table 4. From such observations, it can be suggested that the cellulose pretreatment process starts by reducing the intrachain HBs. This effect was further explored by extracting the cellulose unit cell (composed by five units of cellobiose) from the top and the edge of the cellulose crystallite (Fig. S8a, S9b, S10a, and S11a) along with the closest DES molecules. Then, the strength of the HBs was evaluated through the density functional theory (DFT) calculations (see Supplementary Information for details).

The HBs present in the cellulose unit cell and DES molecules systems were directionally optimized, to calculate the strength of the solute-solvent HBs (in terms of the electronic density, $\rho(\boldsymbol{r})$ ) (Johnson et al. 2010). The results are displayed in Table S2 and Table S3 in the Supplementary Information. The optimized HBs corresponding to the unit cell at the edge of the cellulose crystallite (Table S3), showed largest $\rho(\boldsymbol{r})$ values compared to those related to the unit cell at the top of the cellulose crystallite (Table S2). Furthermore, results from Tables S2 and S3 suggest a synergetic role of the DES molecules towards the cellulose disruption. This is because the $\mathrm{D}-\mathrm{H} \cdots \mathrm{Cl} \mathrm{HBs}$ are largely present at the edge of the cellulose crystallite as well as those related with the HBD or the choline cation, whereas the $D-H \cdots C l$ HBs are not present at the top of the cellulose crystallite for most of the cellulose-DES systems. This synergetic effect at the edge of the cellulose crystallite, probably enhances the breaking of the both intra- and interchain HBs in the solute.

Unfortunately, there was no linear correlation between intra- or interchain HBs and the KamletTaft parameters of DESs, Fig. 4a-b and Fig. S13a-b. However, the slight decrease in the number of intrachain $\mathrm{HBs}$ in $\mathrm{ChCl} /$ ethylene glycol and $\mathrm{ChCl} /$ levulinic acid DESs, suggested that the rate of change (or the slope in Fig. S12) could provide useful information. We calculated this slope $\left(r_{\text {intrachain HBS }}\right)$, obtaining $-0.403,-0.216,-0.277$, and -0.514 intrachain $\mathrm{HBs} / \mathrm{ns}$ for cellulose- $\mathrm{ChCl} / \mathrm{ethylene}$ glycol, cellulose- $\mathrm{ChCl} /$ oxalic acid, cellulose- $\mathrm{ChCl} /$ urea, and cellulose- $\mathrm{ChCl} /$ levulinic acid systems, respectively. 
574 Surprisingly, a meaningful correlation between these values and the Kamlet-Taft $\beta$ and $\alpha$ values is 575 displayed in Fig. 4c and Fig. S13c.

576 The lack of correlation between the intra- or the interchain HBs with the Kamlet-Taft $\beta$ 577 parameter of the DESs and the correlation with $r_{\text {intrachain } H B S}$, might suggest that mass transfer play a 578 relevant role in the cellulose pretreatment with DESs (Ren et al. 2016; Körner et al.; Zhang et al. 2020). 579 Consequently, the diffusion coefficient of the cellulose crystallite in the ChCl-based DESs $580\left(D_{\text {sim,cellulose }-D E}\right)$ was also evaluated through its mean squared displacement and the Einstein relation 581 (Batista et al. 2015). Results are indicated in Table 4 and shown in Fig. 4d and Fig. S13d. Even though it 582 was not found a linear correlation with the Kamlet-Taft $\beta$ and $\alpha$ values $\left(R^{2}=0.20\right.$ and $R^{2}=0.14$, 583 respectively), the larger $D_{\text {sim, cellulose-D }}$ value was found in the $\mathrm{ChCl} /$ ethylene glycol DES $\left(8.38 \times 10^{-1}\right.$ $584 \mathrm{~cm}^{2} / \mathrm{s}$ ) which also presented the smallest experimental viscosity ( $\sim 40 \mathrm{cP}$ ) (D'Agostino et al. 2011).

585 
(a)

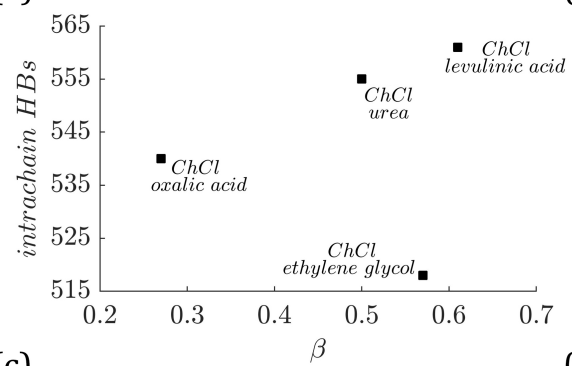

(c)

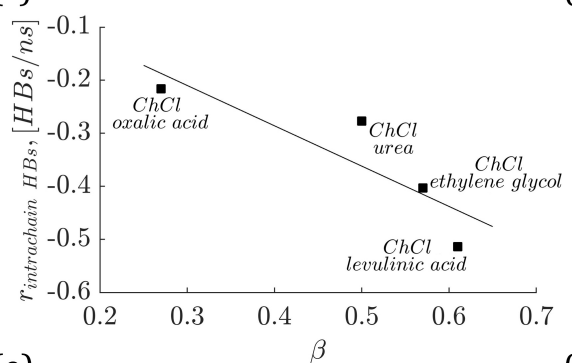

(e)

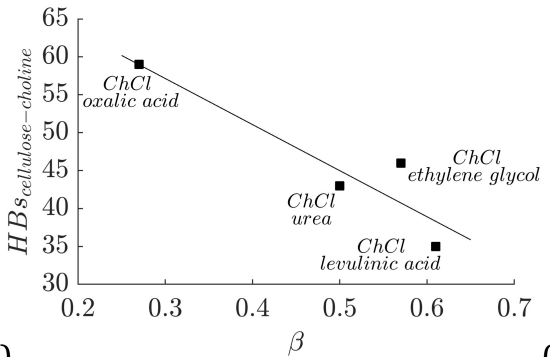

(g)

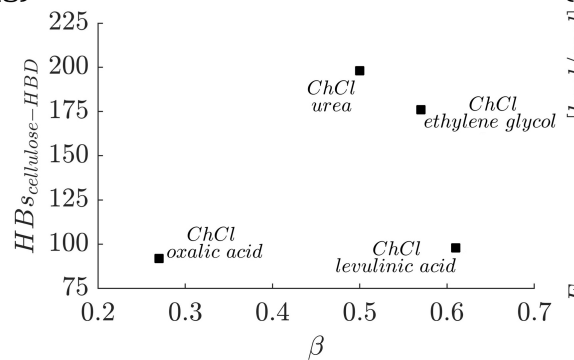

(b)

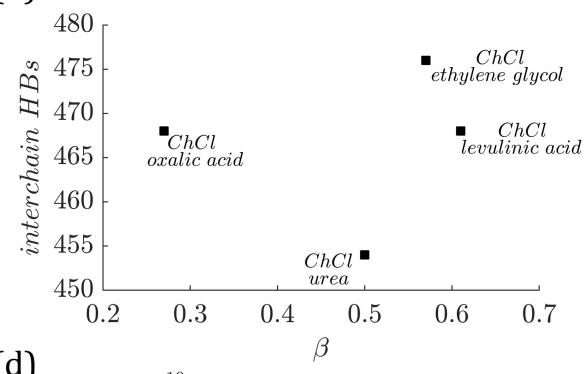

(d)

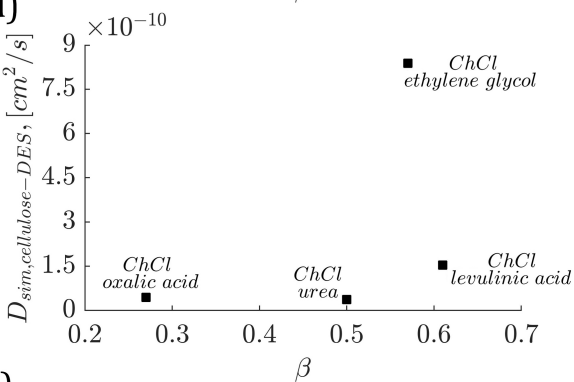

(f)

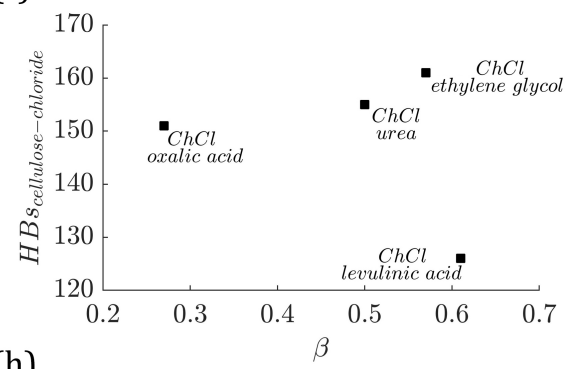

(h)

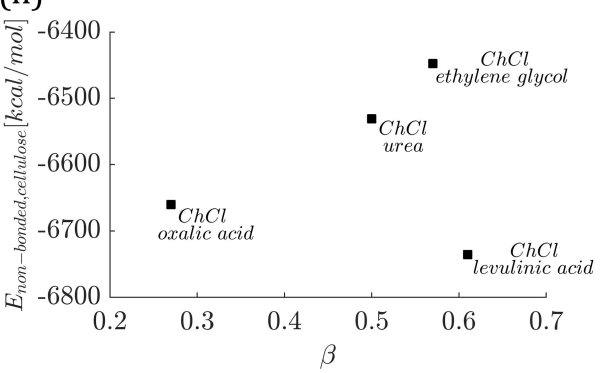

Fig. 4 Linear correlations observed between the Kamlet-Taft $\beta$ parameter and: a Intrachain HBs $\left(R^{2}=0.011\right)$, b Interchain HBs $\left(R^{2}=0.013\right)$, $\mathbf{c}$ Rate of change of intrachain HBs $\left(r_{\text {intrachain } H B S}, R^{2}=0.76\right)$, $\mathbf{d}$ Cellulose diffusion coefficient in DES $\left(D_{\text {sim, cellulose-DE }}, R^{2}=0.20\right)$, e HBs between cellulose crystallite and choline cation $\left(H B s_{\text {cellulose-choli }}, R^{2}=0.86\right), \mathbf{f}$ HBs between cellulose crystallite and chloride anion $\left(H B s_{\text {cellulose-chlori }}, R^{2}=\right.$ $0.10)$, $\mathbf{g}$ HBs between cellulose crystallite and HBD $\left(H B s_{\text {cellulose }-H B D}, R^{2}=0.13\right)$, and $\mathbf{h}$ Non-bonded potential energy of the cellulose crystallite $\left(E_{\text {non-bonded,cellulose }}, R^{2}=0.03\right)$

The HBs between the cellulose crystallite and the choline cation may inhibit the disruption of the cellulose crystallite, since the lower the Kamlet-Taft $\beta$ (or $\alpha$ ) parameter the larger the number of $H B s_{\text {cellulose-choli }}$, as is displayed in the Fig. 4e and Fig. S13e. The large number of $H B s_{\text {cellulose-choline }}$ was found in the $\mathrm{ChCl} /$ oxalic acid DES $(\beta=0.27, \alpha=1.19)$, and could be related to the large $O D-$, and $O C-H A, H S, H S, H D_{D}$ correlations indicated in the RDF analysis, Table 4. These RDF results indicate that the interaction between cellulose and the oxalic acid HBD, is limited. On the other hand, the 
601 small number of $H B s_{\text {cellulose-cho }}$ in the remaining solvents might be a consequence of the largest $\mathrm{Cl}-$ $602 H Y$ and the $\mathrm{Cl}-\mathrm{HO}, \mathrm{HC}, \mathrm{HT}$ distances, limiting the role of the choline cation and thus improving other 603 interactions with cellulose crystallite, such as the larger number of $H B s_{\text {cellulose-HBD }}$. However, based on 604 our results, there was no correlation between $H B s_{\text {cellulose-H }}$ and the Kamlet-Taft parameters of the 605 evaluated ChCl-based DESs $\left(R^{2}=0.13\right.$ in Fig. $4 \mathrm{~g}$ for $\beta$ parameter and $R^{2}=0.08$ in Fig. S13g for $\alpha$ 606 parameter) as would be expected.

607 Finally, for the $H B s_{\text {cellulose-ch }}$, shown in Fig. 4f and Fig. S13f, the largest number of HBs was 608 found for the cellulose-ChCl/ethylene glycol system (161 \pm 8), in concordance with the large distance 609 found for the $\mathrm{Cl}-\mathrm{HY}$ HB in pure DES (i.e., a small interaction between anion and cation). The smallest 610 number of $H B s_{\text {cellulose-chl }}$ (and small number of $H B s_{\text {cellulose-HBD }}$ ) was found in the cellulose$611 \mathrm{ChCl} /$ levulinic acid system. This is in agreement with the stronger $\mathrm{Cl}-\mathrm{HO}$ HBs reported in the pure DES 612 as indicated in Table 3 (and the total $D-H \cdots C l$ HBs shown in Tables S2 and S3), which might hinder 613 better interactions from the levulinic acid HBD towards the cellulose crystallite. It is interesting to note 614 that, from the observations indicated above, the $\mathrm{ChCl} /$ levulinic acid DES seems to be limited by the 615 interactions present between its HBA and HBD.

616 It was found in our previous work (Sánchez-Badillo et al. 2021) that the energetics related to 617 HBs (as suggested the number of stronger HBs reported in Table S2 and S3), their stability, and quality 618 might play a significant role in order to understand better the cellulose pretreatment. For this reasons, 619 HB occupancies were also calculated.

621 HB occupancies. The HB occupancy indicates the percentage of occurrence (or fraction, and thus the 622 stability) of a particular HB along the simulation. Intrachain and interchain HB occupancies in two 623 different sections of the cellulose crystallite: chain 0 (located at the edge of the cellulose crystallite) and 624 625 626 chain 17 (located at the middle of the cellulose crystallite), see the top of Fig. S14, were calculated for all systems (Fig. S14 to S17).

As it can be noted from Fig. S14a-b, S15a-b, S16a-b and S17a-b, the intrachain HB occupancies present in both the chain 17 and chain 0 were related to the typical $O 2-H 2 \cdots O 6, O 3-H 3 \cdots O 5, O 6-$ $H 6 \cdots O 3$, and $06-H 6 \cdots O 2$ HBs found in cellulose I $\beta$ (Shen and Gnanakaran 2009). Despite the chain 0 was surrounded by only two glucan chains, larger intrachain HB occupancies were absent or less frequent than in the chain 17. This suggests also that the cellulose disruption process in DESs started by weakening (or diminishing the HB occupancies of) the chains located at the edge of the cellulose crystallite, in agreement with the stronger unit cell-DES HBs presented in Table S3. On the other hand, the interchain HB occupancies are displayed in Fig. S14c-d, S15c-d, S16c-d, and S17c-d. As observed, the most of the interchain HBs corresponded to the $\mathrm{O} 6-\mathrm{H} 6 \cdots \mathrm{O} 2, \mathrm{O} 6-\mathrm{H} 6 \cdots \mathrm{O}$, and $\mathrm{O} 2-\mathrm{H} 2 \cdots \mathrm{O} 6 \mathrm{HBs}$. The interchain HB occupancies in chain 17 (Fig. S14c, S15c, S16c, and S17c) presented minor variation than those in chain 0 (Fig. S14d, S15d, S16d, and S17d). By comparing such figures, it can be noted that the strong interchain HBs for the glucan at chain 0 in contact with the solvent, were replaced by the $06-$ 
$H 6 \cdots O 4$ HBs. This effect was probably caused by a synergetic effect between the $O-H \cdots C l$, the $C-$ $H \cdots O$, and the $O \cdots H-O$ HBs between cellulose and DES molecules, as suggested the results from DFT calculations shown in Table S2 and Table S3. Detailed discussion regarding the HB occupancies for each cellulose-DES system can be found in the Supplementary Information. The emerging occurrence of the $06-H 6 \cdots 04 \mathrm{HB}$ by action of the DESs, promotes the releasing of the 02 and 03 oxygen atoms, favoring the functionalization of the hydroxyl group and thus the synthesis of cellulose derivatives, required for example, in the acetylation of wood (Sun et al. 2019). This effect suggest the use of the DES as potential sustainable media to synthetize cellulose derivatives due to promotion of the interactions between cellulose and third incorming particles.

The overall effect on the cellulose crystallite disruption caused by DESs from the potential energy of the cellulose crystallite ( $\left.E_{\text {non-bonded,cellulose }}\right)$, was evaluated by computing the single point (molecular mechanics) energy of the final configuration of the cellulose crystallite (shown in Fig. S8a, S9a, S10a, and S11a). The results of $E_{\text {non-bonded,cellulose }}$ are displayed in Table 4. Unfortunately, there was no correlation between $E_{\text {non-bonded,cellulose }}$ and Kamlet-Taft parameters as shown in Fig. $4 \mathrm{~h}$ and Fig. S13h. Hauru et al. (2012) suggested an effective dissolution window, defined as $\beta-\alpha$ in order to correlate the "net basicity" with the dissolution/regeneration of cellulose in water-IL mixtures. Surprisingly, by evaluating this net basicity of the evaluated DESs, a notable correlation with the $E_{n o n-b o n d e d, c e l l u l o s e}$ arises as shown in Fig. S18. Furthermore, other relevant properties including intrachain HBs (Fig. S18a, $R^{2}=0.71$ ), $D_{\text {sim,cellulose-D }} \quad$ (Fig. S18b, $R^{2}=0.39$, partially improved),

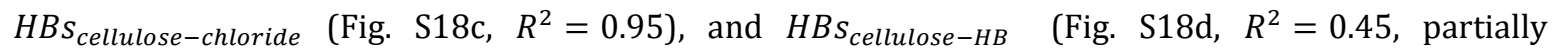
improved) are better correlated towards the net basicity $\beta-\alpha$ definition than with the Kamlet-Taft $\beta$ or $\alpha$ parameters separately. This highlight suggests that both Kamlet-Taft parameters are important in order to understand the role of the DESs in the cellulose pretreatment. However, in order to validate such a hypothesis, a large number of DESs is required. To explore deeper the origin of the observations regarding $E_{\text {non-bonded,cellulose }}$ and Kamlet-Taft $\beta$ and $\alpha$ parameters, the short range (SR) van der Waals and coulombic non-bonded pair energies $\left(E_{S R}\right)$ were evaluated for the all cellulose-DES systems.

Non-bonded pair energies. The $E_{S R}$ were evaluated among the molecules belonging to the groups CEL (i.e. the cellulose crystallite), CHOL (choline cations), $\mathrm{Cl}$ (chloride anions), and HBD in an additional NPT MD simulation of $25 \mathrm{~ns}$ for all cellulose-DES systems. Remaining MD simulation details corresponded to those used in the NPT condensed phase production stage, as indicated in the methodology section. It is important to indicate that the $E_{S R}$ corresponded only to the $L J(S R)$ (van der Waals) and Coul(SR) (electrostatic) terms from the GROMACS energy output file.

The pair energy interactions between cellulose crystallite and DES molecules (cellulose crystallite $\left(E_{S R, C E L-C E L}\right)$, cellulose-choline $\left(E_{S R, C E L-C H O L}\right)$, cellulose-chloride $\left(E_{S R, C E L-C l}\right)$, and cellulose$\left.\operatorname{HBD}\left(E_{S R, C E L-H}\right)\right)$ are displayed in Fig. S19. The largest $E_{S R, C E L-C E L}$ value (more stable cellulose 
674 crystallite) was found within the $\mathrm{ChCl} /$ levulinic acid DES (-47035 kcal/mol in Fig. S19a) in agreement 675 with the large intra- and inter HBs, presented in Table 4. This behavior is probably caused by the small 676 energy contributions from $E_{S R, C E L-C H O L}, E_{S R, C E L-}$, and $E_{S R, C E L-H B D}$ within the ChCl/levulinic acid DES, 677 indicated by the small number of HBs reported in Table S2 and Table S3. On the other hand, the largest 678 interactions towards cellulose crystallite were found in the $\mathrm{ChCl} /$ ethylene glycol and $\mathrm{ChCl} /$ urea DESs 679 (Fig. S19 b-d). This behavior was probably caused by the smallest $\mathrm{HS}-\mathrm{Cl}$ distance (Table 3) as is also 680 suggested by the stronger $O-H \cdots C l$ HBs from Table S3 in the case of $\mathrm{ChCl}$ /ethylene glycol (Fig. S19c); 681 and with both the small $H S-O$ (Table 3, Fig. S19d, and Table S3) and the larger $O D-H A, H W, H S_{D}, H Y$ 682 and $\mathrm{Cl}-\mathrm{HC}, \mathrm{HT}$ distances (Table 3, Fig. S5, Fig. S19b-d) in the case of ChCl/urea. Finally, from Fig. S19b, 683 it can be observed that the $E_{S R, C E L-C H O L}$ was more stable in $\mathrm{ChCl} /$ oxalic acid DES, in agreement with the 684 short distance of the $O D-H A, H W, H S_{D}, H Y$ first peak in the RDFs and the large $N_{\text {coord }}$ shown in Table 6853 , as well as the stronger $O-H \cdots O$ HBs reported in Table S3. These large interactions do not seem to 686 reduce the interactions with $\mathrm{Cl}^{-}$anion (Fig. S19c) when compared with the remaining cellulose-DES 687 systems (see also Table S3); however, a largest reduction in the $E_{S R, C E L-H B D}$ can be noticed. Interestingly, 688 by combining these interaction energy contributions regarding the cellulose crystallite (i.e. $\left.689 E_{S R, C E L-C H O L}+E_{S R, C E L-C l}+E_{S R, C E L-H B D}\right)$ from the DESs with net basicity $(\beta-\alpha)$ definition, a notable 690 correlation is obtained, as shown in Fig. S18f $\left(R^{2}=0.73\right)$, unlike the correlation with the Kamlet-Taft 691 parameters $\beta$ and $\alpha$ separately.

692 It is important to note that, despite the $\mathrm{ChCl} /$ levulinic acid DES had the largest Kamlet-Taft $\beta$ 693 parameter it was not able to disrupt further the cellulose crystallite as indicated by the $E_{S R, C E L-C}$ in Fig. 694 S19a. Additionally, as it was found in the previous section, the cellulose pretreatment with this DES 695 produced the small number of $\mathrm{O} 6-\mathrm{H} 6 \cdots \mathrm{O}$ - HB occupancies compared with the remaining solvents. On 696 this line, it seems that there is a limited role of this DES towards the cellulose crystallite, which it cannot 697 be explained directly by its Kamlet-Taft $\beta$ parameter. In order to explore this point, the $\mathrm{Cl}-\mathrm{CHOL}, \mathrm{Cl}-$ $698 H B D, C H O L-H B D, C H O L-C H O L$ and $H B D-H B D E_{S R}$ were also calculated and displayed in Fig. 5. 699 
(a)

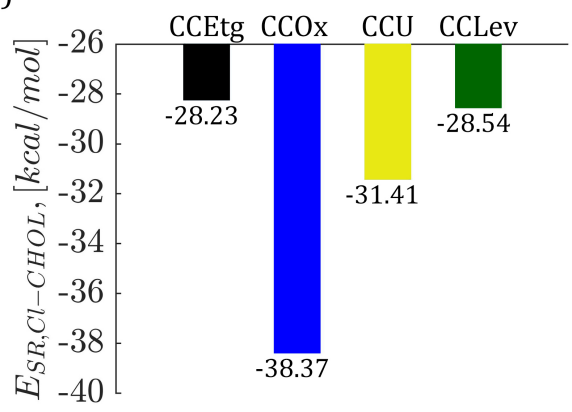

(c)

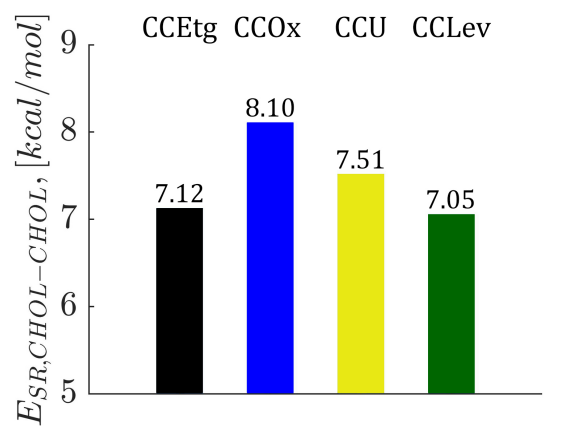

(b)

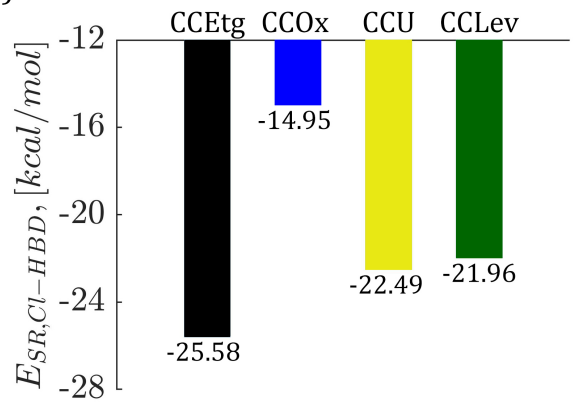

(d)

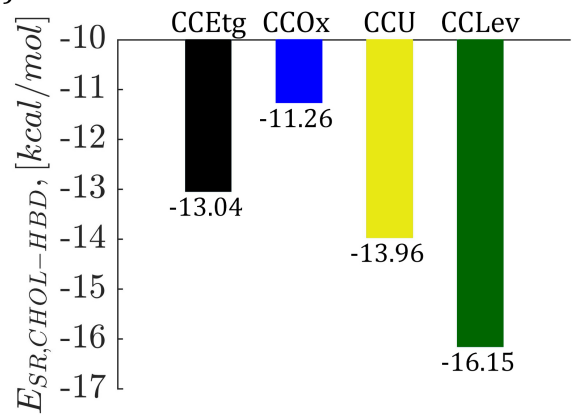

(e)

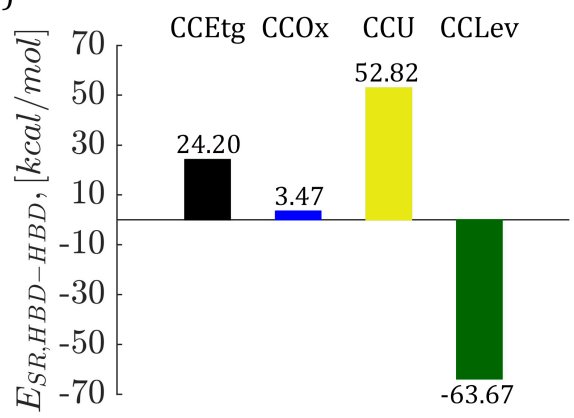
Table S1)

Fig. 5 Calculated non-bonded pair energies $\left(E_{S R}\right)$ for: a Chloride anion and choline cation $\left(E_{S R, C l-C H O L}\right)$, b Chloride anion and hydrogen bond donor $\left(E_{S R, C l-H} \quad\right)$, c Choline cation and hydrogen bond donor $\left(E_{S R, C H O L-H B D}\right)$, d Choline cations $\left(E_{S R, C H O L-C H O L}\right)$, e Hydrogen bond donors $\left(E_{S R, H B D-H B D}\right)$ in cellulose-ChCl/ethylene glycol system (black bar), cellulose-ChCl/oxalic acid (blue bar), cellulose-ChCl/urea (yellow bar), and cellulose-ChCl/levulinic acid (green bar). It should be indicated that, since the number of clusters were different for all cellulose-DES systems, these interactions were scaled by the number of the corresponding DES clusters present in each system (as indicated in

Rapidly, from Fig. 5d-e the interactions between the choline cation and HBD and between HBDs in $\mathrm{ChCl} /$ levulinic acid DES showed the largest negative values ( -16.15 and $-63.67 \mathrm{kcal} / \mathrm{mol}$, respectively) among all the cellulose-DES systems. These interactions within the DES might be the origin of the low cellulose disruption performance as is reported in Table 4 and Fig. S19a, as well as the low correlation displayed in Fig. 4b, 4f, and 4g. This finding suggested that both choline cation and the levulinic acid HBD are both interacting strongly, limiting the role of the DES molecules in the cellulose pretreatment. This effect is also correlated with its smallest net basicity value $(\beta-\alpha=-0.9427)$ among the evaluated DESs. 
717 This competing effect has been reported by Zgrzeba et al. (2015) and by Crowhurst et al. (2003) in ILs, 718 indicating the importance of both Kamlet-Taft parameters.

719 From Fig. 5a, it can be noted that the largest $E_{S R, C l-C H O L}$ was found for the ChCl/oxalic acid DES, 720 in agreement with the observations reported in Table 3 for the small $\mathrm{Cl}-\mathrm{HY}$ interaction distance. 721 Regarding to the $E_{S R, C l-H B}$ in Fig. 5b, the ChCl/oxalic acid DES shows the most positive value (-14.95 $722 \mathrm{kcal} / \mathrm{mol}$ ); this potential advantage over the $\mathrm{Cl}^{-}$anion to interact better with cellulose crystallite, turned 723 also into a large $E_{S R, C l-C H}$ interaction. On the contrary, despite the large value obtained for the $724 E_{S R, C l-H B D}$ in the $\mathrm{ChCl} /$ ethylene glycol DES (-25.58 kcal/mol in Fig. 5b), seems that did not limit the 725 performance of the chloride anion towards the cellulose disruption as reported in Fig. S19a, Fig. S19c, 726 and in Table 4 . This is probably related to the small energy value of the $E_{S R, C l-C H O L}$ interaction, which 727 releases the chloride anion, in agreement with the large $\mathrm{Cl}-H Y$ distance shown in Table 3. Interestingly, 728 the $\mathrm{ChCl} /$ urea and $\mathrm{ChCl} /$ ethylene glycol DESs showed similar $E_{S R, C l-H} \quad$ values (probably related to their 729 similar net basicity values), however, the $\mathrm{ChCl} /$ urea DES also showed the most positive $E_{S R, H B D-H}$ value $730 \quad$ (52.82 kcal/mol in Fig. 5e). Accordingly, there was not competing between urea HBDs to interact with 731 the cellulose crystallite, as is indicated by the large cellulose crystallite disruption shown in Fig. S19a and 732 Table 4.

733 Regarding the role of the interactions between choline cations ( $E_{S R, C H O L-C H} \quad$, Fig. $\left.5 \mathrm{c}\right)$, it can be 734 noticed that all of them were similar and showed a repulsive nature.

Finally, from Fig. 5e, the largest repulsion between HBDs molecules within the DES could 736 promotes a better performance of HBD towards the cellulose crystallite. This is the case of ChCl/ethylene 737 glycol and $\mathrm{ChCl} /$ urea DESs, which also presented the largest $E_{S R, C E L-H}$ as indicated in Fig. S19d, and 738 similar net basicity. In further agreement with the $E_{\text {non-bonde }}$, cellulose values presented in Table 4 . Thus, 739 potential new, green, and sustainable DESs can be selected from their net basicity values not only for an 740 effective cellulose pretreatment but also for lignocellulosic biomass valorization applications.

\section{Conclusions.}

743 It was found by means of molecular dynamics simulations that density, molar volume, cohesive 744 energy density, and Hildebrand parameter of a series of choline-chloride deep eutectic solvents displayed 745 meaningful correlations towards the Kamlet-Taft $\beta$ and $\alpha$ parameters. These results suggest that 746 thermodynamic properties can be used as a qualitative measure of the cellulose pretreatment process at 747 low temperature. Further insights indicated that $\mathrm{Cl}-\mathrm{HY}$ interactions in conjunction with its 748 corresponding $N_{\text {coord }}$ within the solvent, could be an indicative of the hydrogen bond network strength. 749 The last impacts the interaction of the $\mathrm{Cl}^{-}$anion towards the hydrogen atoms in the hydroxyl groups 750 from glucose units as occurred in the choline-chloride ethylene glycol deep eutectic solvent.

751 Analysis regarding the cellulose crystallite and DESs suggested that the $\mathrm{HS}-\mathrm{Cl}$ and the $O D-$ 752 HO hydrogen bonds play a relevant role in the deformation or disruption of the cellulose crystallite. 
Interestingly, the $O D-H O$ interactions between glucose units and hydrogen bond donor presented shorter distances than the $\mathrm{HS}-\mathrm{Cl}$ interaction. Furthermore, it was found that substantial $\mathrm{HS}-$ oxygen interactions between cellulose and hydrogen bond donor were obtained for $R-C O-R$ structures within the hydrogen bond donor.

Analysis of the hydrogen bonds within the cellulose crystallite indicated that the intrachain hydrogen bonds were reduced first compared to the interchain hydrogen bonds. Additionally, the hydrogen bond occupancies indicated that the stronger $06-\mathrm{H}_{6} \cdots \mathrm{O} 2 / \mathrm{O} 3$ and $\mathrm{O} 2-\mathrm{H} 2 \cdots \mathrm{O}$ - interchain hydrogen bonds are present in the inner chains. Interestingly, the same analysis revealed that such hydrogen bonds are slightly reduced and replaced by weak $06-H 6 \cdots O 4$ hydrogen bonds in the glucan located at the edge, i.e., chains in direct contact with the solvent.

The analysis of the atomistic properties of the cellulose crystallite did not show a complete correlation with the Kamlet-Taft $\beta$ or $\alpha$ parameters separately. Interestingly, both parameters need to be considered to achieve correlations with such properties, by means of the net basicity $(\beta-\alpha)$ for each DES.

Energetic analysis from the pair energies contributions suggested that even though the cholinechloride levulinic acid has the largest Kamlet-Taft $\beta$ parameter (0.61) among the evaluated solvents, it also presented a larger hydrogen bond donor-hydrogen bond donor pair energy interaction, which strongly limited the role of the levulinic acid towards cellulose crystallite.

Summarizing, for the evaluated choline-chloride-based deep eutectic solvents, effective solvents for the cellulose pretreatment could be related (but not limited) with the following: low density, low cohesive energy density, Hildebrand parameter around $30 \mathrm{MPa}{ }^{0.5}$, large molar volume, $R-C O-R$ moieties within the HBD, a large net basicity value, and small HBD-HBD interaction. Fortunately, all these properties can be obtained through in-silico evaluations, providing relevant insights for the development of new, sustainable, and more efficient DESs solvents for the cellulose pretreatment.

\section{Acknowledgments.}

J.S.-B. acknowledges a postdoctoral fellowship from CONACYT grant. All authors acknowledge the computational resources provided by the Departamento de Química de la División de Ciencias Básicas e Ingeniería at Universidad Autónoma Metropolitana unidad Iztapalapa (UAMI), as well as the computational resources provided by Dr. Raúl González-García at Universidad Autónoma de San Luis Potosí (UASLP).

\section{Declaration.}

\section{Conflict of interest.}

The authors declare that they have no conflict of interest. 
This article does not contain any studies with human beings or animals.

\section{Supplementary information.}

The number of molecules for each system modeled in this work is indicated in Table S1. Atomic labels and molecular structures are shown in Fig. $\mathrm{S} 1$ for the reader convenience. The final configuration of the cellulose-DES systems is shown in Fig. S2. Linear correlations observed between Kamlet-Taft $\alpha$ parameter and the same thermodynamic properties shown in Fig. 2, are displayed in Fig. S3. RDFs for searching possible HBs between cellulose crystallite and DESs are shown in Fig. S4 to Fig. S6, respectively. RDFs for searching possible HBs within choline-chloride and between choline-chloride and HBD are displayed in Fig. S7. The final molecular configuration of the cellulose crystallite along with a closed view to the disrupted chains within the DESs are shown in Fig. S8 to Fig. S11. The calculated number of (total, interchain, intrachain, cellulose crystallite-choline cation, cellulose crystallite-choline-chloride anion, and cellulose crystallite-choline HBD) HBs is shown in Fig. S12. Electronic density of the HBs between cellulose unit cell extracted from top and edge of the cellulose crystallite and DES molecules, obtained by DFT calculations, are displayed in Table S2 and Table S3. Linear correlations observed between KamletTaft $\alpha$ parameter and the same atomistic properties shown in Fig. 4, are displayed in Fig. S13. Intrachain and interchain HB occupancies for chain 17 and chain 0 within DESs are shown in Fig. S14 to S17. Linear correlations observed between net basicity $(\beta-\alpha)$ and atomistic properties of the cellulose crystallite are shown in Fig. S18. Finally, the calculated non-bonded pair energies within the cellulose crystallite and between cellulose crystallite and DES molecules are shown in Fig. S19.

811

\section{References}

Abo-Hamad A, Hayyan M, AlSaadi MA, Hashim MA (2015) Potential applications of deep eutectic solvents in nanotechnology. Chem Eng J 273:551-567. https://doi.org/10.1016/j.cej.2015.03.091

Abraham MJ, Murtola T, Schulz R, Páll S, Smith JC, Hess B, Lindahl E (2015) GROMACS: High performance molecular simulations through multi-level parallelism from laptops to supercomputers. SoftwareX 12:19-25. https://doi.org/10.1016/j.softx.2015.06.001

Adamo C, Barone V (1999) Toward reliable density functional methods without adjustable parameters: The PBE0 model. J Chem Phys 110:6158-6169. http://doi.org/10.1063/1.478522

822 modeling program, applied chemical theory (IMPACT). J Comput Chem 26:1752-1780. 
Batista MLS, Pérez-Sánchez G, Gomes JRB, Coutinho JAP, Maginn EJ (2015) Evaluation of the GROMOS

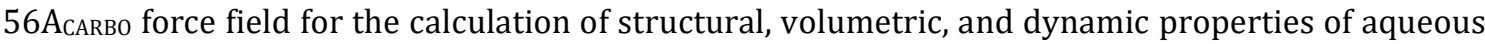
glucose systems. J Phys Chem B 119:15310-15319. https://doi.org/10.1021/acs.jpcb.5b08155

Berendsen HJC, Postma JPM, van Gunsteren WF, Dinola A, Haak JR (1984) Molecular dynamics with coupling to an external bath. J Chem Phys 81:3684-3690. https://doi.org/10.1063/1.448118

Brehm M, Thomas M, Gehrke S, Kirchner B (2020) TRAVIS-A free analyzer for trajectories from molecular simulation. J Chem Phys 152:164105. https://doi.org/10.1063/5.0005078

Brett CMA (2018) Deep eutectic solvents and applications in electrochemical sensing. Curr Opin Electrochem 10:143-148. https://doi.org/10.1016/j.coelec.2018.05.016

Bussi G, Donadio D, Parrinello M (2007) Canonical sampling through velocity rescaling. J Chem Phys 126:014101. https://doi.org/10.1063/1.2408420

Chemat F, Anjum H, Shariff AM, Kumar P, Murugesan T (2016) Thermal and physical properties of (choline chloride + urea + l-arginine) deep eutectic solvents. J Mol Liq 218:301-308. https://doi.org/10.1016/j.molliq.2016.02.062

Chen Y, Mu T. Application of deep eutectic solvents in biomass pretreatment and conversion (2019) Green Energy Environ 4:95-115. https://doi.org/10.1016/i.gee.2019.01.012

Chen Y-L, Zhang X, You T-T, Xu F (2019) Deep eutectic solvents (DESs) for cellulose dissolution: A minireview. Cellulose 26:205-213. https://doi.org/10.1007/s10570-018-2130-7

Clarke CJ, Tu W-C, Levers O, Bröhl A, Hallett JP (2018) Green and sustainable solvents in chemical processes. Chem Rev 118:747-800. https://doi.org/10.1021/acs.chemrev.7b00571

Crowhurst L, Mawdsley PR, Perez-Arlandis JM, Salter PA, Welton T (2003) Solvent-solute interactions in ionic liquids. Phys Chem Chem Phys 5:2790-2794. https://doi.org/10.1039/b303095d

Cruz JC, Hernández-Esparza R, Vázquez-Mayagoitia Á, Vargas R, Garza J (2019) Implementation of the molecular electrostatic potential over graphics processing. J Chem Inf Model 59:3120-3127. http://doi.org/10.1021/acs.jcim.8b00951

D'Agostino C, Harris RC, Abbott AP, Gladden LF, Mantle MD (2011) Molecular motion and ion diffusion in choline chloride based deep eutectic solvents studied by ${ }^{1} \mathrm{H}$ pulsed field gradient NMR spectroscopy. Phys Chem Chem Phys 13:21383-21391. https://doi.org/10.1039/c1cp22554e

Doherty B, Acevedo 0 (2018) OPLS force field for choline chloride-based deep eutectic solvents. J Phys Chem B 122:9982-9993. https://doi.org/10.1021/acs.jpcb.8b06647

Doherty B, Zhong X, Acevedo $O$ (2018) Virtual site OPLS force field for imidazolium-based ionic liquids. J Phys Chem B 122:2962-2974. https://doi.org/10.1021/acs.jpcb.7b11996

Dwamena AK, Raynie DE (2020) Solvatochromic parameters of deep eutectic solvents: Effect of different carboxylic acids as hydrogen bond donor. J Chem Eng Data 65:640-646. https://doi.org/10.1021/acs.jced.9b00872

Essmann U, Perera L, Berkowitz ML, Darden T, Lee H, Pedersen LG (1995) A smooth particle mesh Ewald method. J Chem Phys 103:8577-8592. https://doi.org/10.1063/1.470117 
861 Faggian M, Sut S, Perissutti B, Baldan V, Grabnar I, Dall'Acqua S (2016) Natural deep eutectic solvents

862

863

864

865

866

867

868

869

870

871

872

873

874

875

876

877

878

879

880

881

882

883

884

885

886

887

888

889

890

891

892

893

894

895

896

897 (NADES) as a tool for bioavailability improvement: Pharmacokinetics of rutin dissolved in proline/glycine after oral administration in rats: Possible application in nutraceuticals. Molecules 21:1531. https://doi.org/10.3390/molecules21111531

Ferreira ESC, Voroshylova IV, Pereira CM, Cordeiro MNDS (2016) Improved force field model for the deep eutectic solvent ethaline: Reliable physicochemical properties. J Phys Chem B 120:10124-10137. https://doi.org/10.1021/acs.jpcb.6b07233

Florindo C, McIntosh AJS, Welton T, Branco LC, Marrucho IMA (2018) Closer look into deep eutectic solvents: Exploring intermolecular interactions using solvatochromic probes. Phys Chem Chem Phys 20:206-213. https://doi.org/10.1039/c7cp06471c

Florindo C, Oliveira FS, Rebelo LPN, Fernandes AM, Marrucho IM (2014) Insights into the synthesis and properties of deep eutectic solvents based on cholinium chloride and carboxylic acids. ACS Sustainable Chem Eng 2:2416-2425. https://doi.org/10.1021/sc500439w

Francisco M, van den Bruinhorst A, Kroon MC (2012) New natural and renewable low transition temperature mixtures (LTTMs): Screening as solvents for lignocellulosic biomass processing. Green Chem 14:2153-2157. DOI: https://doi.org/10.1039/c2gc35660k

Fu H, Wang X, Sang H, Hou Y, Chen X, Feng X (2020) Dissolution behavior of microcrystalline cellulose in BDU-based deep eutectic solvents: Insights from spectroscopic investigation and quantum chemical calculations. J Mol Liq 299:112140. https://doi.org/10.1016/j.molliq.2019.112140

García G, Aparicio S, Ullah R, Atilhan M (2015) Deep eutectic solvents: Physicochemical properties and gas separation applications. Energy Fuels 29:2616-2644. https://doi.org/10.1021/ef5028873

Gomes TCF, Skaf MS (2012) Cellulose-builder: A toolkit for building crystalline structures of cellulose. J Comput Chem 33:1338-1346. https://doi.org/10.1002/icc.22959

Gontrani L, Bonomo M, Plechkova NV, Dini D, Caminiti R (2018) X-Ray structure and ionic conductivity studies of anhydrous and hydrated choline chloride and oxalic acid deep eutectic solvents. Phys Chem Chem Phys 20:30120-30124. https://doi.org/10.1039/c8cp06728g

Gorke JT, Srienc F, Kazlauskas RJ (2008) Hydrolase-catalyzed biotransformations in deep eutectic solvents. Chem Commun 1235-1237. https://doi.org/10.1039/b716317g

Grimme S, Antony J, Ehrlich S, Krieg H (2010) A consistent and accurate ab initio parametrization of density functional dispersion correction (DFT-D) for the 94 elements H-Pu. J Chem Phys 132:154104. http://doi.org/10.1063/1.3382344

Gunny AAN, Arbain D, Nashef EM, Jamal P (2015) Applicability evaluation of deep eutectic solventscellulase system for lignocellulose hydrolysis. Bioresour Technol 181:297-302. https://doi.org/10.1016/j.biortech.2015.01.057

Häkkinen R, Abbott A (2019) Solvation of carbohydrates in five choline chloride-based deep eutectic solvents and the implication for cellulose solubility. Green Chem 21:4673-4682. https://doi.org/10.1039/C9GC00559E 
Halder AK, Cordeiro MNDS (2019) Probing the environmental toxicity of deep eutectic solvents and their components: An in silico modeling approach. ACS Sustainable Chem Eng 7:10649-10660. https://doi.org/10.1021/acssuschemeng.9b01306

Harifi-Mood AR, Buchner R (2017) Density, viscosity, and conductivity of choline chloride + ethylene glycol as a deep eutectic solvent and its binary mixtures with dimethyl sulfoxide. J Mol Liq 225:689695. https://doi.org/10.1016/j.molliq.2016.10.115

Hauru LKJ, Hummel M, King AWT, Kilpeläinen I, Sixta H (2012) Role of solvent parameters in the regeneration of cellulose from ionic liquid solutions. Biomacromolecules 13:2896-2905. https://doi.org/10.1021/bm300912y

Hernández-Esparza R, Mejía-Chica S-M, Zapata-Escobar AD, Guevara-García A, Martínez-Melchor A, Hernández-Pérez J-M, Vargas R, Garza J (2014) Grid-based algorithm to search critical points, in the electron density, accelerated by graphics processing units. J Comput Chem 35:2272-2278. http://doi.org/10.1002/jcc.23752

Hernández-Esparza R, Vázquez-Mayagoitia Á, Soriano-Agueda L-A, Vargas R, Garza J (2019) GPUs as boosters to analyze scalar and vector fields in quantum chemistry. Int J Quantum Chem 119:e25671. http://doi.org/10.1002/qua.25671

Hess B, Bekker H, Berendsen JC, Fraaije JGEM (1997) LINCS: A linear constraint solver for molecular simulations. J Comput Chem 18:1463-1472. https://doi.org/10.1002/(SICI)1096987X(199709)18:12<1463::AID-JCC4>3.0.CO;2-H

Humphrey W, Dalke A, Schulten K (1996) VMD: Visual molecular dynamics. J Mol Graphics 14:33-38. https://doi.org/10.1016/0263-7855(96)00018-5

Johnson ER, Keinan S, Mori-Sánchez P, Contreras-García J, Cohen AJ, Yang W (2010) Revealing noncovalent interactions. J Am Chem Soc 132:6498-6506. https://doi.org/10.1021/ja100936w

Kalhor P, Ghandi K (2019) Deep eutectic solvents for pretreatment, extraction, and catalysis of biomass and food waste. Molecules 24:4012. https://doi.org/10.3390/molecules24224012

Körner S, Albert J, Held C (2019) Catalytic low-temperature dehydration of fructose to 5hydroxymethylfurfural using acidic deep eutectic solvents and polyoxometalate catalysts. Front Chem 7:661. https://doi.org/10.3389/fchem.2019.00661

Kubicki JD, Yang H, Sawada D, O'Neill H, Oehme D, Cosgrove D (2018) The shape of native plant cellulose microfibrils. Sci Rep 8:13983. https://doi.org/10.1038/s41598-018-32211-w

Kumar B, Bhardwaj N, Agrawal K, Chaturvedi V, Verma P. (2020) Current perspective on pretreatment technologies using lignocellulosic biomass: An emerging biorefinery concept. Fuel Process Technol 199:106244. https://doi.org/10.1016/j.fuproc.2019.106244

Kundu D, Rao PS, Banerjee T (2020) First principle prediction of Kamlet-Taft solvatochromic parameters of deep eutectic solvent using COSMO-RS model. Ind Eng Chem Res 59:11329-11339. https://doi.org/10.1021/acs.iecr.0c00574 
Lapeña D, Lomba L, Artal M, Lafuente C, Giner B (2019) Thermophysical characterization of the deep eutectic solvent choline chloride:ethylene glycol and one of its mixtures with water. Fluid Phase Equilib 492:1-9. https://doi.org/10.1016/j.fluid.2019.03.018

Lawes SDA, Hainsworth SV, Blake P, Ryder KS, Abbott AP (2010) Lubrication of steel/steel contacts by choline chloride ionic liquids. Tribol Lett 37:103-110. https://doi.org/10.1007/s11249-009-9495-6

Leron RB, Li M-H (2012) High-pressure density measurements for choline chloride: Urea deep eutectic solvent and its aqueous mixtures at $\mathrm{T}=(298.15$ to 323.15$) \mathrm{K}$ and up to $50 \mathrm{MPa}$. J Chem Thermodyn 54:293-301. https://doi.org/10.1016/i.jct.2012.05.008

Leron RB, Soriano AN, Li M-H (2012) Densities and refractive indices of the deep eutectic solvents (choline chloride + ethylene glycol or glycerol) and their aqueous mixtures at the temperature ranging from 298.15 to $333.15 \mathrm{~K}$. J Taiwan Inst Chem Eng 43:551-557. https://doi.org/10.1016/i.jtice.2012.01.007

Li Y, Liu X, Zhang S, Yao Y, Yao X, Xu J, Lu X (2015) Dissolving process of a cellulose bunch in ionic liquids: A molecular dynamics study. Phys Chem Chem Phys 17:17894-17905. https://doi.org/10.1039/c5cp02009c

Liang X, Zhu Y, Qi B, Li S, Luo J, Wan Y (2021) Structure-property-performance relationships of lactic acid-based deep eutectic solvents with different hydrogen bond acceptors for corn stover pretreatment. Bioresour Technol 336:125312. https://doi.org/10.1016/j.biortech.2021.125312

Liu H, Sale KL, Holmes BM, Simmons BA, Singh S (2010) Understanding the interactions of cellulose with ionic liquids: A molecular dynamics study. J Phys Chem B 114:4293-4301. https://doi.org/10.1021/ip9117437

Liu Z, Wu X, Wang W (2014) A novel united-atom force field for imidazolium-based ionic liquids. Phys Chem Chem Phys 8:1096-1104. https://doi.org/10.1039/b515905a

Lu W, Alam MA, Pan Y, Wu J, Wang Z, Yuan Z (2016) A new approach of microalgal biomass pretreatment using deep eutectic solvents for enhanced lipid recovery for biodiesel production. Bioresour Technol 218:123-128. https://doi.org/i.biortech.2016.05.120

Lungwitz R, Spange S (2008) A hydrogen bond accepting (HBA) scale for anions, including room temperature ionic liquids. New J Chem 32:392-394. https://doi.org/10.1039/b714629a

Martínez L, Andrade R, Birgin EG, Martínez JM (2009) Packmol: A package for building initial configurations for molecular dynamics simulations. J Comput Chem 30:2157-2164. https://doi.org/10.1002/jcc.21224

Mohan M, Naik PK, Banerjee T, Goud VV, Paul S (2017) Solubility of glucose in tetrabutylammonium bromide based deep eutectic solvents: Experimental and molecular dynamic simulations. Fluid Phase Equilib 448:168-177. https://doi.org/10.1016/j.fluid.2017.05.024

Morais ES, da Costa Lopes AM, Freire MG, Freire CSR, Coutinho JAP, Silvestre AJD (2020) Use of ionic liquids and deep eutectic solvents in polysaccharides dissolution and extraction processes towards sustainable biomass valorization. Molecules 25:3652. https://doi.org/10.3390/molecules25163652 
971 Nishiyama Y, Langan P, Chanzy H (2002) Crystal structure and hydrogen-bonding system in cellulose I $\beta$ from synchrotron X-ray and neutron fiber diffraction. J Am Chem Soc 124:9074-9082. https://doi.org/10.1021/ja0257319

Perdew JP, Burke K, Ernzerhof M (1996) Generalized gradient approximation made simple. Phys Rev Lett 77:3865-3868. http://doi.org/10.1103/PhysRevLett.77.3865

Perdew JP, Burke K, Ernzerhof M (1997) Generalized gradient approximation made simple. Phys Rev Lett 78:1396. http://doi.org/10.1103/PhysRevLett.78.1396

Pinkert A, Marsh KN, Pang S, Staiger MP (2009) Ionic liquids and their interaction with cellulose. Chem Rev 109:6712-6728. https://doi.org/10.1021/cr9001947

Procentese A, Johnson E, Orr V, Campanile AG, Wood JA, Marzocchella A, Rehmann L (2015) Deep eutectic solvent pretreatment and subsequent saccharification of corncob. Bioresour Technol 192:31-36. https://doi.org/10.1016/j.biortech.2015.05.053

Rabideau BD, Agarwal A, Ismail AE (2013) Observed mechanism for the breakup of small bundles of cellulose I $\alpha$ and I $\beta$ in ionic liquids from molecular dynamics simulations. J Phys Chem B 117:34693479. https://doi.org/10.1021/jp310225t

Rabideau BD, Agarwal A, Ismail AE (2014) The role of the cation in the solvation of cellulose by imidazolium based ionic liquids. J Phys Chem B 118:1621-1629. https://doi.org/10.1021/ip4115755

Rabideau BD, Ismail AE (2015) Mechanisms of hydrogen bond formation between ionic liquids and cellulose and the influence of water content. Phys Chem Chem Phys 17:5767-5775. https://doi.org/10.1039/c4cp04060k

Ravula S, Larm NE, Mottaleb MA, Heitz MP, Baker GA (2019) Vapor pressure mapping of ionic liquids and low-volatility fluids using graded isothermal thermogravimetric analysis. ChemEngineering 3:42. https://doi.org/10.3390/chemengineering3020042

Ren H, Chen C, Wang Q, Zhao D, Guo S (2016) The properties of choline chloride-based deep eutectic solvents and their performance in the dissolution of cellulose. BioResources 11:5435-5451. https://doi.org/10.15376/biores.11.2.5435-5451

Rinaldi R, Reece J (2017) Solution-based deconstruction of (ligno)-cellulose. In: Behrens M, Datye AK (eds) Catalysis for the conversion of biomass and its derivatives. WILEY-VCH Verlag, Weinheim, pp. 435-462

Rocha EGA, Pin TC, Rabelo SC, Costa AC (2017) Evaluation of the use of protic ionic liquids on biomass fractionation. Fuel 206:145-154. https://doi.org/10.1016/j.fuel.2017.06.014

Rodríguez NR, González ASB, Tijssen PMA, Kroon MC (2015) Low transition temperature mixtures (LTTMs) as novel entrainers in extractive distillation. Fluid Phase Equilib 385:72-78. https://doi.org/10.1016/j.fluid.2014.10.044

Salehi HS, Ramdin M, Moultos OA, Vlugt TJH (2019) Computing solubility parameters of deep eutectic solvents from molecular dynamics simulations. Fluid Phase Equilib 497:10-18. https://doi.org/10.1016/j.fluid.2019.05.022 
1008

1009

1010

1011

1012

1013

1014

1015

1016

1017

1018

1019

1020

1021

1022

1023

1024

1025

1026

1027

1028

1029

1030

1031

1032

1033

1034

1035

1036

1037

1038

1039

1040

1041

1042

1043

1044

Sánchez-Badillo JA, Gallo M, Rutiaga-Quiñones JG, López-Albarrán P (2021) Solvent behavior of an ionic liquids set around a cellulose $\mathrm{I} \beta$ crystallite model through molecular dynamics simulations. Cellulose 28:6767-6795. https://doi.org/10.1007/s10570-021-03992-7

Sert M, Aslanoğlu A, Ballice L (2018) Conversion of sunflower stalk based cellulose to the valuable products using choline chloride based deep eutectic solvents. Renewable Energy 118:993-1000. https://doi.org/10.1016/j.renene.2017.10.083

Shahbaz K, Baroutian S, Mjalli FS, Hashim MA, AlNashef IM (2012) Densities of ammonium and phosphonium based deep eutectic solvents: Prediction using artifical intelligence and group contribution techniques. Thermochim Acta 527:59-66. https://doi.org/10.1016/j.tca.2011.10.010

Shahbaz K, Mjalli FS, Vakili-Nezhaad G, AlNashef IM, Asadov A, Farid MM (2016) Thermogravimetric measurement of deep eutectic solvents vapor pressure. J Mol Liq 222:61-66. https://doi.org/10.1016/i.molliq.2016.06.106

Sharma M, Mukesh C, Mondal D, Prasad K (2013) Dissolution of $\alpha$-chitin in deep eutectic solvents. RSC Adv 3:18149-18155. https://doi.org/10.1039/C3RA43404D

Shekaari H, Zafarani-Moattar MT, Mohammadi B (2017) Thermophysical characterization of aqueous deep eutectic solvent (choline chloride/urea) solutions in full ranges of concentration at $\mathrm{T}=(293.15-$ 323.15) K. J Mol Liq 243:451-461. https://doi.org/10.1016/j.molliq.2017.08.051

Shen T, Gnanakaran S (2009) The stability of cellulose: A statistical perspective from a coarse-grained model of hydrogen-bond networks. Biophys J 96:3032-3040. https://doi.org/10.1016/i.bpj.2008.12.3953

Sirviö JA, Visanko M, Liimatainen H (2015) Deep Eutectic solvent system based on choline chloride-urea as a pre-treatment for nanofibrillation of wood cellulose. Green Chem 17:3401-3406. https://doi.org/10.1039/c5gc00398a

Smirnov MA, Sokolova MP, Tolmachev DA, Vorobiov VK, Kasatkin IA, Smirnov NN, Klaving AV, Bobrova NV, Lukasheva NV, Yakimansky AV (2020) Green method for preparation of cellulose nanocrystals using deep eutectic solvent. Cellulose 27:4305-4317. https://doi.org/10.1007/s10570-020-03100-1

Smith EL, Abbott AP, Ryder KS (2014) Deep eutectic solvents (DESs) and their applications. Chem Rev 114:11060-11082. https://doi.org/10.1021/cr300162p

Stalker MR, Grant J, Yong CW, Ohene-Yeboah LA, Mays TJ, Parker SC (2021) Molecular simulation of hydrogen storage and transport in cellulose. Mol Simul 47:170-179. https://doi.org/10.1080/08927022.2019.1593975

Stortz CA, Johnson GP, French AD, Csonka GI (2009) Comparison of different force fields for the study of disaccharides. Carbohydr Res 344:2217-2228. https://doi.org/10.1016/j.carres.2009.08.019

Sun B, Chai Y, Liu J, Militz H (2019) Acetylation of plantation softwood without catalysts or solvents. Wood Res 64:799-810.

Swatloski RP, Spear SK, Holbrey JD, Rogers RD (2002) Dissolution of cellulose with ionic liquids. J Am Chem Soc 124:4974-4975. https://doi.org/10.1021/ja025790m 
Tang X, Zuo M, Li Z, Liu H, Xiong C, Zeng X, Sun Y, Hum L, Liu S, Lei T, Lin L (2017) Green processing of lignocellulosic biomass and its derivatives in deep eutectic solvents. ChemSusChem 10:2696-2706. https://doi.org/10.1002/cssc.201700457

Tiong YW, Yap CL, Gan S, Yap WSP (2018) Conversion of biomass and its derivatives to levulinic acid and levulinate esters via ionic liquids. Ind Eng Chem Res 57:4749-4766. https://doi.org/10.1021/acs.iecr.8b00273

Trache D (2018) Nanocellulose as a promising sustainable material for biomedical applications. AIMS Mater Sci 5:201-205. https://doi.org/10.3934/matersci.2018.2.201

Trache D, Thakur VK, Boukherroub R (2020) Cellulose nanocrystals/graphene hybrids-A promising new class of materials for advanced applications. Nanomaterials 10:1523. https://doi.org/10.3390/nano10081523

Ufimtsev IS, Martínez TJ (2008) Quantum chemistry on graphical processing units. 1. Strategies for twoelectron integral evaluation. J Chem Theory Comput 4:222-231. http://doi.org/10.1021/ct700268q

Ünlü AE, Arıkaya A, Takac S (2019) Use of deep eutectic solvents as catalyst: A mini-review. Green Process Synth 8:355-372. https://doi.org/10.1515/gps-2019-0003

van Osch DJGP, Kollau LJBM, van den Bruinhorst A, Asikainen S, Rocha MAA, Kroon MC (2017) Ionic liquids and deep eutectic solvents for lignocellulosic biomass fractionation. Phys Chem Chem Phys 19:2636-2665. https://doi.org/10.1039/c6cp07499e

van Putten R-J, van der Waal JC, de Jong E, Rasrendra CB, Heeres HJ, de Vries JG (2013) Hydroxymethylfurfural, a versatile platform chemical made from renewable resources. Chem Rev 113:1499-1597. https://doi.org/10.1021/cr300182k

Velioglu S, Yao X, Devémy J, Ahunbay MG, Tantekin-Ersolmaz SB, Dequidt A, Costa Gomes MF, Pádua AAH (2014) Solvation of a cellulose microfibril in imidazolium acetate ionic liquids: Effect of a cosolvent. J Phys Chem B 118:14860-14869. https://doi.org/10.1021/jp508113a

Wang H, Gurau G, Rogers RD (2012) Ionic liquid processing of cellulose. Chem Soc Rev 41:15191537. https://doi.org/10.1039/c2cs15311d

Welton $T$ (2015) Solvents and sustainable chemistry. Proc R Soc A 471:20150502. https://doi.org/10.1098/rspa.2015.0502

Xia Q, Liu Y, Meng J, Cheng W, Chen W, Liu S, Liu Y, Li J, Yu H (2018) Multiple hydrogen bond coordination in three-constituent deep eutectic solvent enhances lignin fractionation from biomass. Green Chem 20:2711-2721. https://doi.org/10.1039/C8GC00900G

Xia S, Baker GA, Li H, Ravula S, Zhao H (2014) Aqueous ionic liquids and deep eutectic solvents for cellulosic biomass pretreatment and saccharification. RSC Adv 4:10586-10596. https://doi.org/10.1039/c3ra46149a

Xie Y, Dong H, Zhang S, Lu X, Ji X (2014) Effect of water on the density, viscosity, and $\mathrm{CO}_{2}$ solubility in choline chloride/urea. J Chem Eng Data 59:3344-3352. https://doi.org/10.1021/je500320c 
1081 Yadav A, Kar JR, Verma M, Naqvi S, Pandey S (2015) Densities of aqueous mixtures of (choline chloride + 1082 ethylene glycol) and (choline chloride + malonic acid) deep eutectic solvents in temperature range

1083

1084

1085

1086

1087

1088

1089

1090

1091

1092

1093

1094

1095

1096

1097

1098

1099

1100

1101

1102

1103 283.15-363.15 K. Thermochim Acta 600:95-101. https://doi.org/10.1016/j.tca.2014.11.028

Yadav A, Pandey S (2014) Densities and viscosities of (choline chloride + urea) deep eutectic solvent and its aqueous mixtures in the temperature range 293.15 K to 363.15 K. J Chem Eng Data 59:2221-2229. https://doi.org/10.1021/je5001796

Zgrzeba A, Andrzejewska E, Marcinkowska A (2015) Ionic liquid-containing ionogels by thiol-ene photopolymerization. Kinetics and solvent effect. RSC Adv 5:100354-100361. https://doi.org/10.1039/c5ra21254e

Zhang H, Lang J, Lan P, Yang H, Lu J, Wang Z (2020) Study on the dissolution mechanism of cellulose by ChCl-based deep eutectic solvents. Materials 13:278. https://doi.org/10.3390/ma13020278

Zhang Q, Benoit M, De Oliveira Vigier K, Barrault J, Jérôme F (2012) Green and inexpensive cholinederived solvents for cellulose decrystallization. Chem Eur J 18:1043-1046. https://doi.org/10.1002/chem.201103271

Zhang Z, Song J, Han B (2017) Catalytic transformation of lignocellulose into chemicals and fuel products in ionic liquids. Chem Rev 117:6834-6880. https://doi.org/10.1021/acs.chemrev.6b00457

Zhong X, Liu Z, Cao D (2011) Improved classical united-atom force field for imidazolium-based ionic liquids: Tetrafluoroborate, hexafluorophosphate, methylsulfate, trifluoromethylsulfonate, acetate, trifluoroacetate, and bis(trifluoromethylsulfonyl)amide. J Phys Chem B 115:10027-10040. https://doi.org/10.1021/jp204148q

Zhou S, Jin K, Buehler MJ (2020) Understanding plant biomass via computational modeling (2020) Adv Mater 2003206. https://doi.org/10.1002/adma.202003206 


\section{Supplementary Files}

This is a list of supplementary files associated with this preprint. Click to download.

- DESCellulosefeb142022SI.pdf 